\title{
Creep of Cold-Drawn Nickel
}

\author{
William D. Jenkins and Carl R. Johnson
}

(March 18, 1959)

\begin{abstract}
Creep tests were made in tension under constant loads at temperatures of $300^{\circ}, 700^{\circ}$, $900^{\circ}$, and $1,200^{\circ} \mathrm{F}$ on specimens of nickel initially cold-drawn to 40 -percent reduction in area None of the equations for defining the strain-time relationship proposed by other investigators was found to be suitable to express or predict the creep-test results of this investigation with high accuracy because these equations inadequately describe the changes in structure accompanying the creep processes. However, conformance to the parabolic strain-time law was obtained over limited ranges of stresses and strains. The effects of cold-drawing on the creep properties are discussed. Certain etching techniques were employed that gave evidence of the presence and movement of dislocations in the structure.
\end{abstract}

\section{Introduction}

During the past few years, a number of theories have been proposed to describe the creep behavior of metal specimens subjected to constant applied stress at constant temperature. The degree of success in the application of the theories to experimental creep data depends on the reality of the models used. Generally, it is accepted that the rate-determining factor during creep is the motion of defects (primarily dislocations) through the crystal lattice by thermal activiation under the action of an applied stress. As more accurate data are accumulated, the role of the instantaneous structure of metals during creep appears to become increasingly important.

An extensive review of the current literature on theories of creep has been presented in a recent symposium [9]. ${ }^{1}$ Therefore, only selected references, pertinent to the present data, will be made in this paper, with a discussion of the results obtained in this investigation.

A comprehensive investigation designed to evaluate the influence of stress, strain, strain rate, temperature, and structure on the rheological properties of nickel, copper, and nickel-copper alloys has been in progress at the Bureau and the results have been published in several papers [1 to 8]. The present phase of the study was made to evaluate the influence of stress and cold-drawing to 40-percent reduction in area (hereafter referred to as "cold-drawn") on the creep characteristics of nickel at $300^{\circ}, 700^{\circ}$, $900^{\circ}$, and $1,200^{\circ} \mathrm{F}$. The selected temperatures are $0.24,0.37,0.44$, and 0.53 , respectively, of the melting temperature $\left(1,726^{\circ} \mathrm{K}\right)$ of nickel. Data derived from previously published values for annealed nickel [5] are included for purposes of comparison with the data for the cold-drawn metal.

\section{Material and Procedures}

The nickel used in this study was prepared by

\footnotetext{
${ }^{1}$ Figures in brackets indicate the literature references at the end of this paper.
}

induction melting, and all bars were processed from one 14- by 14- by 60-in. ingot. This ingot was milled, then forged to 8- by 8-in. blooms, and hotrolled to $2 \frac{1}{2}$-in.-square billets. The material was then hot-rolled to $1 \frac{5}{3} 2_{2}$-in.-diam bars and annealed for $16 \mathrm{hr}$ at $1,100^{\circ} \mathrm{F}$ plus $8 \mathrm{hr}$ at $1,000^{\circ} \mathrm{F}$ to produce the desired grain size. The nickel was then centerless ground to $1 \frac{1 / 8}{8}-\mathrm{in}$. diam and cold-drawn to $7 / 8-i n$. diam. Chemical, spectrochemical, and vacuumfusion analyses made on this ingot of nickel gave the following impurities (percentage by weight): 0.009 $\mathrm{Cu}, 0.04 \mathrm{Fe}, 0.03 \mathrm{Mn}, 0.11 \mathrm{Si}, 0.007 \mathrm{C}, 0.002 \mathrm{~S}$, $<0.01 \mathrm{Co}, 0.001 \mathrm{O}_{2}, 0.001 \mathrm{~N}_{2}$, and $0.0002 \mathrm{H}_{2}$.

All specimens were made from the same bar of nickel that was cold-drawn to 40-percent reduction in area by the manufacturer. This bar was from the same ingot of nickel from which specimens were obtained for evaluating its high-temperature tensile properties [7] and creep properties of the annealed stock [5]. Creep specimens were machined to a 0.505-in. diameter over a 2-in. reduced section. Each creep specimen was heated in air to the desired temperature before loading to the required stress in increments equivalent to a stress of $5,333 \mathrm{lb} / \mathrm{in}^{2}$ applied at 1-hr intervals.

The temperatures of the creep furnaces were controlled within $\pm 1^{\circ} \mathrm{F}$ of the desired values over the specimen length, and the probable error in measuring the extension increments was less than 0.00002 in. Contours of the specimens after testing were determined by measuring the diameters at various distances from the fracture. Rockwell hardness determinations were made along the longitudinal axis of the fractured specimens according to procedures adopted in reference [1].

Recommended procedures were used for preparation of specimens by mechanical means for metallographic examination. However, several special etching techniques, described later in this paper, were also used.

The test data are summarized in table 1 and plotted in figures 1 to 13 , inclusive. 
TABLE 1. Test conditions and results of creep tests on high-purity nickel, initially cold-drawn to 40 -percent reduction in area

\begin{tabular}{|c|c|c|c|c|c|c|c|c|c|c|c|c|c|}
\hline \multirow{2}{*}{$\begin{array}{l}\text { Specimen } \\
\text { No. }\end{array}$} & \multirow{2}{*}{$\begin{array}{l}\text { Test } \\
\text { temper- } \\
\text { ature }\end{array}$} & \multirow{2}{*}{$\begin{array}{l}\text { Creep } \\
\text { stress }\end{array}$} & \multicolumn{2}{|c|}{ Plastic strain } & \multirow{2}{*}{$\begin{array}{l}\text { A verage } \\
\text { creep } \\
\text { rate, } \\
\text { second } \\
\text { stage }\end{array}$} & \multicolumn{2}{|c|}{$\begin{array}{l}\text { Beginning of } \\
\text { third stage }\end{array}$} & \multicolumn{5}{|c|}{ End of test } & \multirow[b]{2}{*}{ Remarks } \\
\hline & & & $\begin{array}{l}1 \text { hour } \\
\text { after } \\
\text { appli- } \\
\text { cation } \\
\text { of load }\end{array}$ & $\begin{array}{c}\text { Inter- } \\
\text { cept at } \\
\text { zero } \\
\text { time }\end{array}$ & & Time & $\begin{array}{l}\text { Plastic } \\
\text { strain }\end{array}$ & Time & $\begin{array}{l}\text { Elonga- } \\
\text { tion }\end{array}$ & $\begin{array}{l}\text { Reduc- } \\
\text { tion of } \\
\text { area }\end{array}$ & $\begin{array}{l}\text { True strain } \\
\text { at fracture }\end{array}$ & $\begin{array}{l}\text { True stress } \\
\text { at fracture }\end{array}$ & \\
\hline A-17. & ${ }^{\circ} F$ & $\begin{array}{l}\text { lb/in. } .^{2} \\
72,000\end{array}$ & $\begin{array}{l}\% \\
0.15\end{array}$ & $\begin{array}{l}\% \\
0.46\end{array}$ & $\begin{array}{c}\% / 1.000 \mathrm{hr} \\
0\end{array}$ & $h r$ & $\%$ & $\begin{array}{r}h r \\
2,297\end{array}$ & $\begin{array}{l}\% \\
\text { a } 0.46\end{array}$ & $\begin{array}{l}\% \\
{ }^{\circ} 0.4\end{array}$ & $\log _{\mathrm{e}}\left(A_{\mathrm{o}} / A\right)$ & $l b / i n .^{2}$ & Test stopped in second \\
\hline A-19_-- & 300 & 75,000 & .47 & .37 & 75 & 2.5 & 0.61 & 3.2 & 18.5 & 76.4 & 1.442 & 317,000 & Tested to complete frac- \\
\hline A-20 & 300 & 75,600 & & .13 & 1,270 & 0.15 & .32 & 0.25 & 18 & 78.1 & 1.518 & 345,000 & Do. \\
\hline A-10. & 700 & 42,670 & 0 & .07 & 0.42 & 425 & .25 & 2,091 & 26.8 & 82.1 & 1. 722 & 238,000 & Do. \\
\hline $\mathrm{A}-4$ & 700 & 48,000 & .11 & .17 & 4.12 & 80 & .5 & 164. 3 & 23.0 & 83.4 & 1. 793 & 288,000 & Do. \\
\hline $\begin{array}{l}\mathrm{A}-18 \ldots \ldots \\
\mathrm{A}-8\end{array}$ & $\begin{array}{l}700 \\
700\end{array}$ & $\begin{array}{l}51,500 \\
53,330\end{array}$ & $\begin{array}{r}.26 \\
2.01\end{array}$ & $\begin{array}{l}.23 \\
.15\end{array}$ & $\begin{array}{l}21.4 \\
670\end{array}$ & $\begin{array}{c}14 \\
0.6\end{array}$ & $\begin{array}{l}.56 \\
.55\end{array}$ & $\begin{array}{r}27.8 \\
1.2\end{array}$ & $\begin{array}{l}22 \\
23.5\end{array}$ & $\begin{array}{l}87.8 \\
83.6\end{array}$ & $\begin{array}{l}2.064 \\
1.808\end{array}$ & $\begin{array}{l}300,000 \\
325,000\end{array}$ & $\begin{array}{l}\text { Do. } \\
\text { Do. }\end{array}$ \\
\hline A-15 & 900 & 24,000 & 0.01 & .19 & 0.67 & 1,320 & 1.08 & 3,546 & 42 & 84.5 & 1.863 & 154,000 & Do. \\
\hline A-12.. & 900 & 26,670 & .06 & .31 & 1. 66 & 800 & 1. 62 & 1,746 & 30.0 & 82.2 & 1.721 & 149,000 & Do. \\
\hline A-9 & 900 & 32,000 & .11 & .17 & 6.55 & 165 & 1. 25 & 452 & 30.3 & 85.0 & 1. 901 & 213,000 & Do. \\
\hline$A-5 \ldots$ & 900 & 37,330 & .35 & .30 & 61 & 9 & 0.85 & 44.5 & 33.5 & 89.5 & 2. 219 & 343,000 & Do. \\
\hline A-16.... & 900 & 40,000 & .51 & .29 & 200 & 3.2 & .93 & 7.5 & 24.5 & 82.8 & 1.761 & 232,000 & Do. \\
\hline A-11 $\ldots . .$. & 1,200 & 2,665 & .15 & 1. 2 & 1. 24 & 2,100 & 3.8 & 4,853 & a 8.5 & b 7.5 & & & $\begin{array}{l}\text { Test stopped in third } \\
\text { stage }\end{array}$ \\
\hline$A-6 \ldots$ & 1,200 & 4,010 & .40 & 1.75 & 7.9 & 500 & 5. 7 & 3,825 & 74.5 & 78.8 & 1.554 & 19,000 & $\begin{array}{l}\text { Tested to complete frac- } \\
\text { ture. }\end{array}$ \\
\hline $\begin{array}{l}A-7 \\
A-14\end{array}$ & $\begin{array}{l}1,200 \\
1,200\end{array}$ & $\begin{array}{l}6,670 \\
9,330\end{array}$ & $\begin{array}{l}1.88 \\
6.72\end{array}$ & $\begin{array}{l}4.15 \\
7.6\end{array}$ & $\begin{array}{l}72.6 \\
632\end{array}$ & $\begin{array}{l}58.5 \\
21.2\end{array}$ & $\begin{array}{l}8.4 \\
21\end{array}$ & $\begin{array}{l}86 \\
25.3\end{array}$ & $\begin{array}{l}97.3 \\
625\end{array}$ & $\begin{array}{l}97.6 \\
97.8\end{array}$ & $\begin{array}{l}3.745 \\
3.839\end{array}$ & $\begin{array}{l}281,000 \\
433,000\end{array}$ & $\begin{array}{l}\text { Do. } \\
\text { Do. }\end{array}$ \\
\hline
\end{tabular}

a These values are for plastic strain as the specimens did not break.

b These values are for contraction of area as the specimens did not break.

\section{Results and Discussion}

\subsection{Effect of Stress and Temperature on Strain-Time Relations}

Hazlett and Parker [10] indicated that creep curves for high-purity nickel specimens, tested at constant stress within the temperature range $550^{\circ}$ to $700^{\circ} \mathrm{C}$, contained no region of constant creep rate and could be represented over a temperature range by the equation

where

$$
\epsilon-\epsilon_{0}=B t^{b} e^{-Q / R T}
$$

$\epsilon=$ total true strain,

$\epsilon_{0}=$ instantaneous true strain at loading,

$B$ and $b=$ parameters, varying with grain size and other metallurgical factors,

$t=$ time,

$Q=$ activation energy,

$R=$ gas constant, and

$T=$ absolute temperature in degrees Kelvin.

Conrad and Robertson [11] have recently reviewed the work of the above authors and applied this parabolic time law to other data obtained on closepacked hexagonal metals. They concluded that a recovery mechanism, occurring above 0.4 the melting temperature, was associated with this law. Below this temperature, the negative curvature of some of the log strain-log time plots for magnesium specimens necessitated the use of a negative value of $\epsilon_{0}$. From a physical standpoint, a negative strain on loading has no significance.

Strain-time data for the specimens of the colddrawn nickel used in the present investigation were plotted on a linear scale. These curves (not shown) were similar to those previously given $[1,2,5,8]$ and indicated the existence of a first, second, and third stage of creep; however, the stages were more clearly defined in the tests conducted at high temperatures than at low temperatures. Values derived from the data are summarized in table 1 . The relation between log plastic strain ${ }^{2}$ and log time is shown in figure 1. Although small portions of the curves appear to be linear, the general trend is a positive curvature. Only one curve of this family showed a negative curvature (the specimen tested at $300^{\circ} \mathrm{F}$ with a stress of $72,000 \mathrm{lb} / \mathrm{in}^{2}{ }^{2}$. A linear relation could not be established in all the curves of figure 1 by any selection of $\epsilon_{0}$ values.

Andrade [12] pointed out that there were many points of similarity between creep curves obtained under various test conditions and that it would be possible by simple transposition to derive the creep curve of one metal from data obtained on another metal at the same fraction of their melting temperatures. In order to ascertain the degree of similarity between strain-time curves of long and short duration, several methods were used for evaluating the behaviour of the cold-drawn nickel. The data for some of the specimens are plotted using plastic strain as a function of the ratio of time to fracture time (fig. 2) and the ratio of plastic strain to elongation at fracture as a function of the ratio of time to fracture time (fig. 3). It is apparent that no appreciable coincidence was obtained for the curves for specimens of nickel tested at the same temperature at different stresses or at different temperatures and stresses when the data were evaluated in this manner. The curvatures and the relative positions

2 The values for plastic strain were taken as equal to the total strain minus the elastic strain as derived from the modulus of elasticity and the stress. 


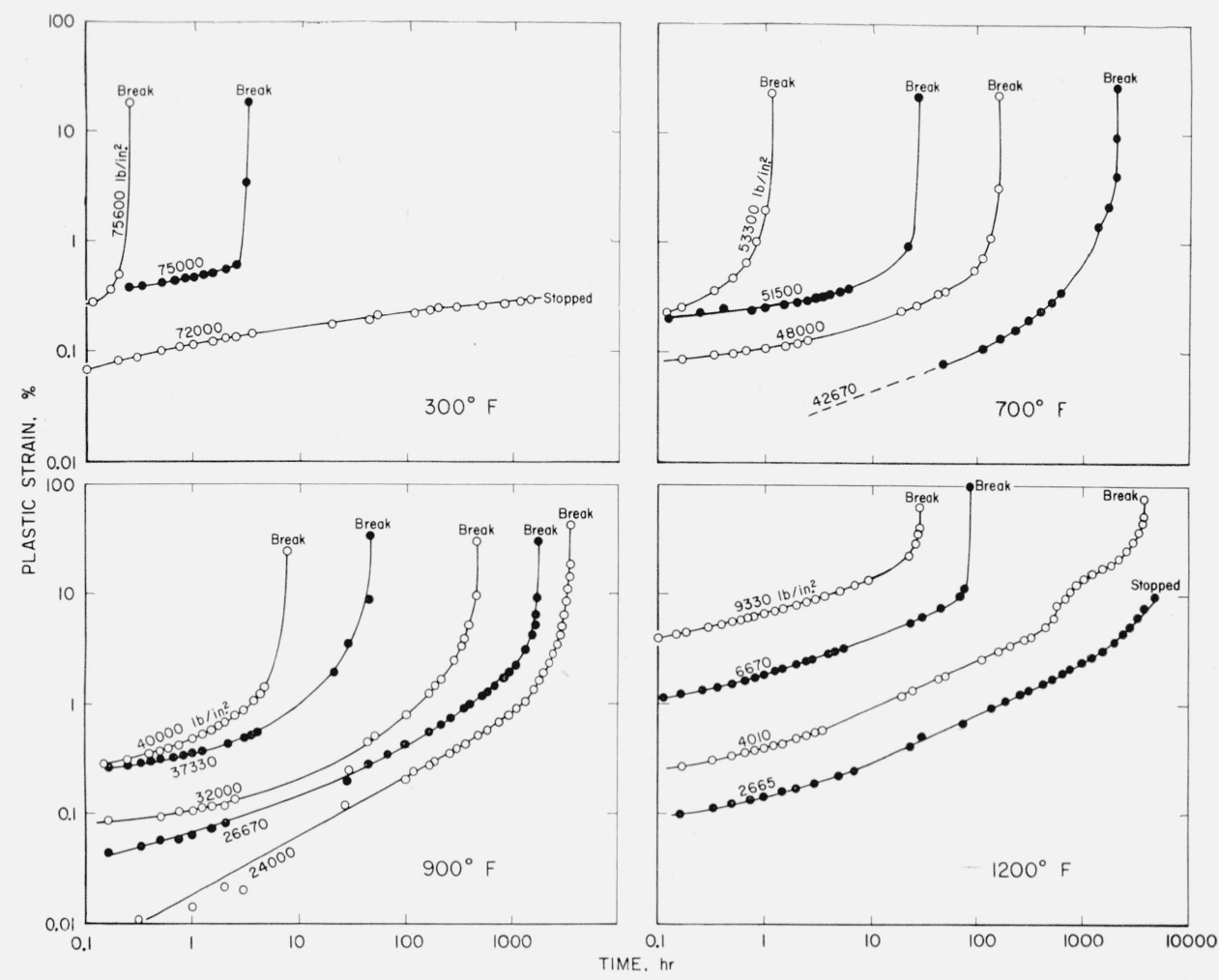

FiguRE 1. Strain-time curves for the initially cold-drawn nickel specimens tested in creep.

of the curves, however, can be related to the structural changes occurring during the creep test and to the ductility resulting from the action of the applied stress on the motion of the lattice defects. At $700^{\circ} \mathrm{F}$, where the predominating mechanism for creep was assumed to be the intersection of dislocations threading the glide plane [11], the curves merge more nearly than at $1,200^{\circ} \mathrm{F}$ where both recovery and recrystallization occur.

\subsection{Effect of Temperature and Stress on Second- Stage Creep Rate}

McVetty [13] concluded that the second-stage creep rate varies linearly with the hyperbolic sine of the stress. Thus for large values of stress, the $\log$ creep rate becomes proportional to the stress. A similar relation was proposed by Dushman and collaborators [14]. The equation was of the form

$$
\log _{e}(\dot{\epsilon} / T)=(-A / T)-C+K \sigma,
$$

where

$\dot{\epsilon}$ represents the second-stage creep rate,

$T$ is absolute temperature in degrees Kelvin,

$\sigma$ is stress,

$A$ and $C$ are constants, and

$K$ is a parameter dependent on temperature.

Therefore, at constant temperature,

$$
\log \dot{\epsilon}=C_{1}+C_{2} \sigma,
$$

where $C_{1}$ and $C_{2}$ are constants. This is the logarithmic rate law often used for the presentation of creep data.

The relation between stress and logarithm of the second-stage creep rate of the cold-drawn nickel specimens used in the present investigation is shown in figure 4. At test temperatures of $700^{\circ}$ and $900^{\circ}$ F a negative curvature is observed; whereas, at $1,200^{\circ} \mathrm{F}$, within the same range of creep rates, a positive curvature exists. A positive curvature of the stress-creep rate curve is interpreted as a confirmation of the generally accepted theory that creep at relatively high temperatures takes place by a diffusion-controlled mechanism.

For engineering applications, it is common practice to describe the applied creep stress in relation to the short-time tensile strength at the designated temperatures. This ratio was plotted against the second-stage creep rate for both the cold-drawn and annealed nickel used in a previous investigation [5] and the results are shown in figure 5. The two families of curves are of the same general shape as those shown in figure 4 for the cold-drawn metal and for the annealed metal. At $700^{\circ}$ or $900^{\circ} \mathrm{F}$, the curves for the cold-drawn material are significantly above the corresponding curves for the annealed nickel although the two curves for specimens tested at $700^{\circ} \mathrm{F}$ tend to converge at the higher creep rates. At $1,200^{\circ} \mathrm{F}$, however, the strengthening effect of cold-drawing is removed and the curves are quite similar for each of the initial conditions. This is to be expected, as $1,200^{\circ} \mathrm{F}$ is above the recrystalliza- 


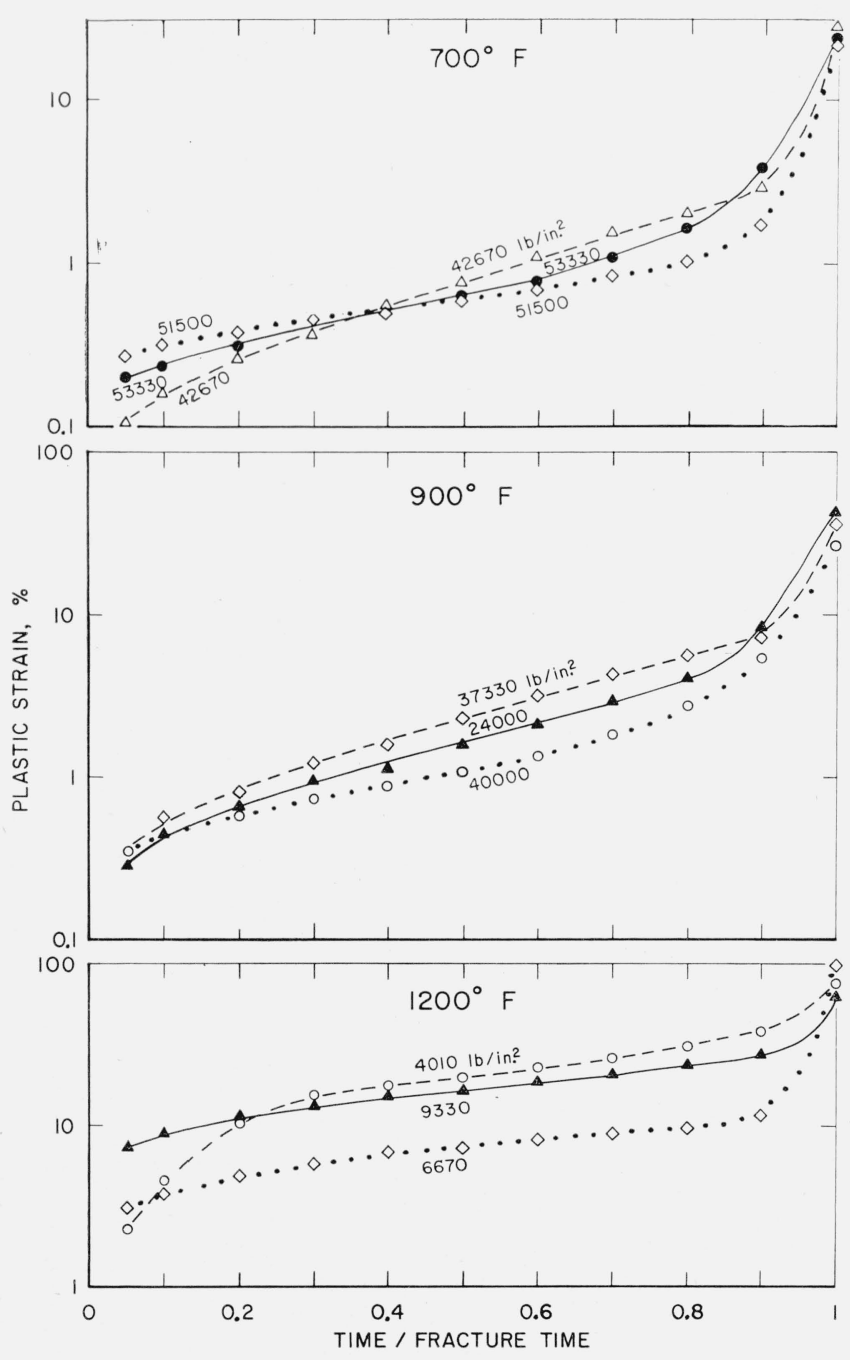

FIgURE 2. Relation of plastic strain to the time-fracture time ratio for the cold-drawn nickel.

tion temperature of the cold-drawn nickel. Suificient tests were not made at $300^{\circ} \mathrm{F}$ on the annealed nickel to definitely establish the trend, but apparently cold-drawing had no material effect on the magnitude of the ratio. It is noteworthy that the curve for the cold-drawn nickel at $900^{\circ} \mathrm{F}$ and for the annealed nickel at $700^{\circ} \mathrm{F}$ nearly coincide.

A linear relation is obtained when the logarithm of the stress is plotted against the logarithm of the second-stage creep rate for a number of materials. Using this relation Lubahn [15] proposed the following equation:

$$
n=\left[\frac{\partial \log \sigma}{\partial \log \dot{\epsilon}}\right]_{T}
$$

where $n=$ "rate sensitivity", $\sigma=$ stress, and $\dot{\epsilon}=$ second-stage creep rate at temperature, $T$.

The quantity, $n$, for Lubahn's data appeared to be strongly dependent on the test temperature. Approximately linear relations (curves not shown) were obtained when the logarithm of the creep

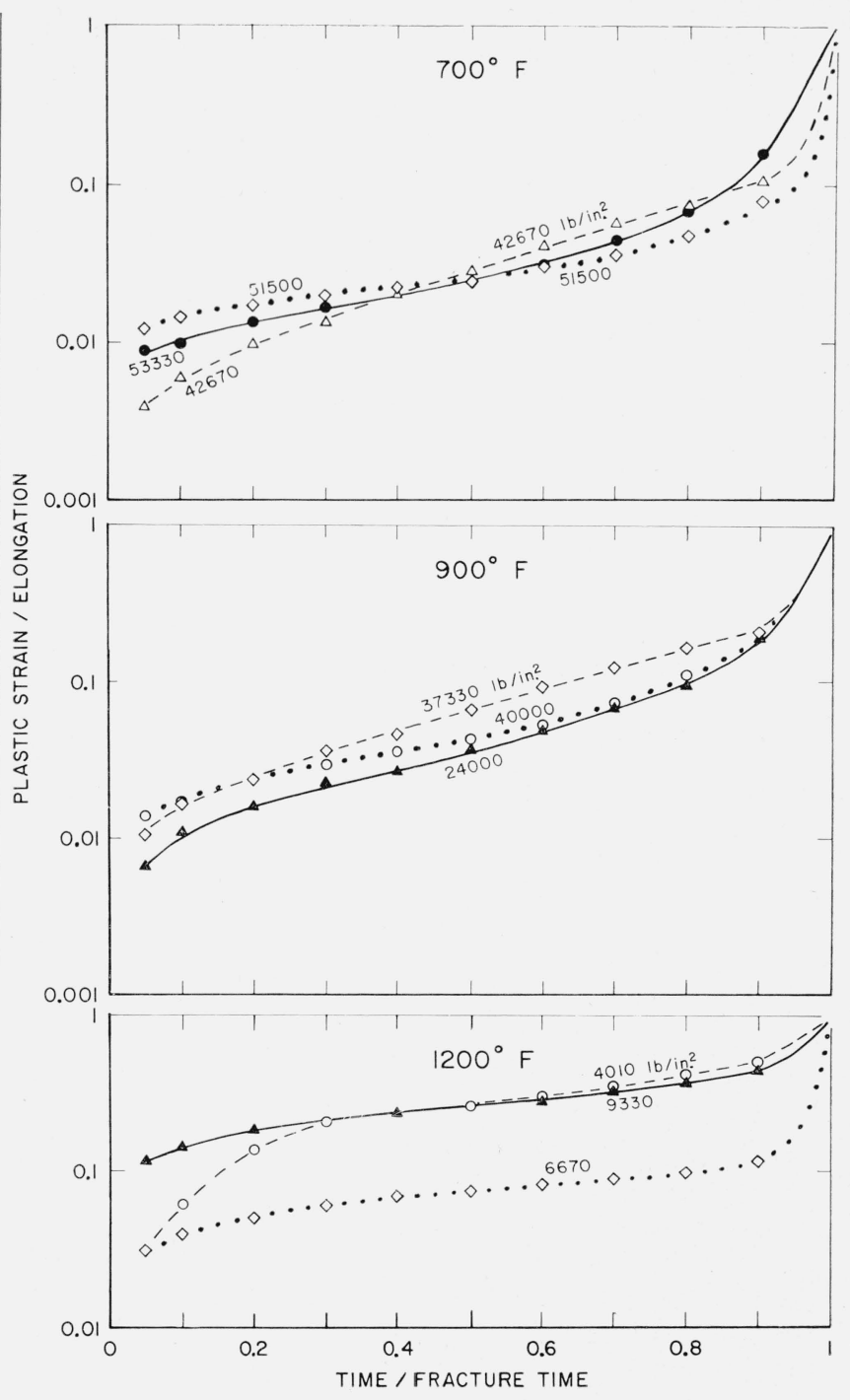

FiguRE 3. Relation of the plastic strain-elongation ratio to the time-fracture time ratio for the cold-drawn nickel.

stress was plotted against the logarithm of the second-stage creep rate for the specimens used in the present investigation. Rate sensitivities were obtained from the slopes of the curves.

The effect of temperature on the rate sensitivity for both the annealed and cold-drawn nickel is shown in figure 6 . It is apparent that the rate sensitivity of the nickel decreases with decrease in test temperature and with cold-drawing. The greatest decrease due to cold-drawing appears to exist in the region of $700^{\circ} \mathrm{F}$.

The relation between stress and temperature to produce selected constant creep rates of 1,10 , or 100 percent per $1,000 \mathrm{hr}$ at different temperatures for cold-drawn nickel is shown in figure 7. The tendency is for the curves to converge at $300^{\circ} \mathrm{F}$ to a single value equal almost to the short-time tensile strength at this temperature. Within the limits of the creep data shown, the greatest divergence of the curves is observed at $900^{\circ} \mathrm{F}$. 


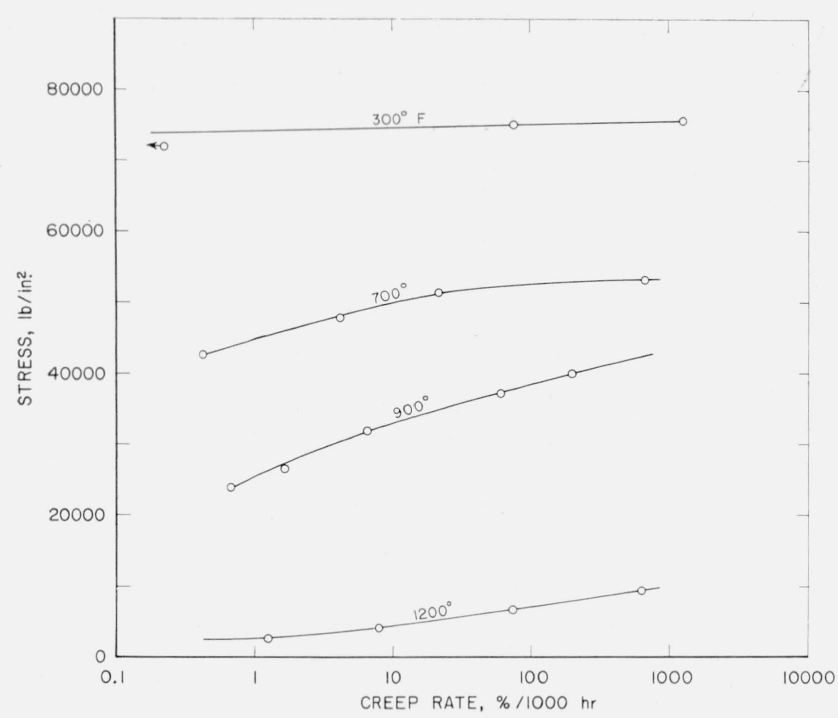

FIGURE 4. Effect of stress on the average second-stage creep rate of the cold-drawn nickel.

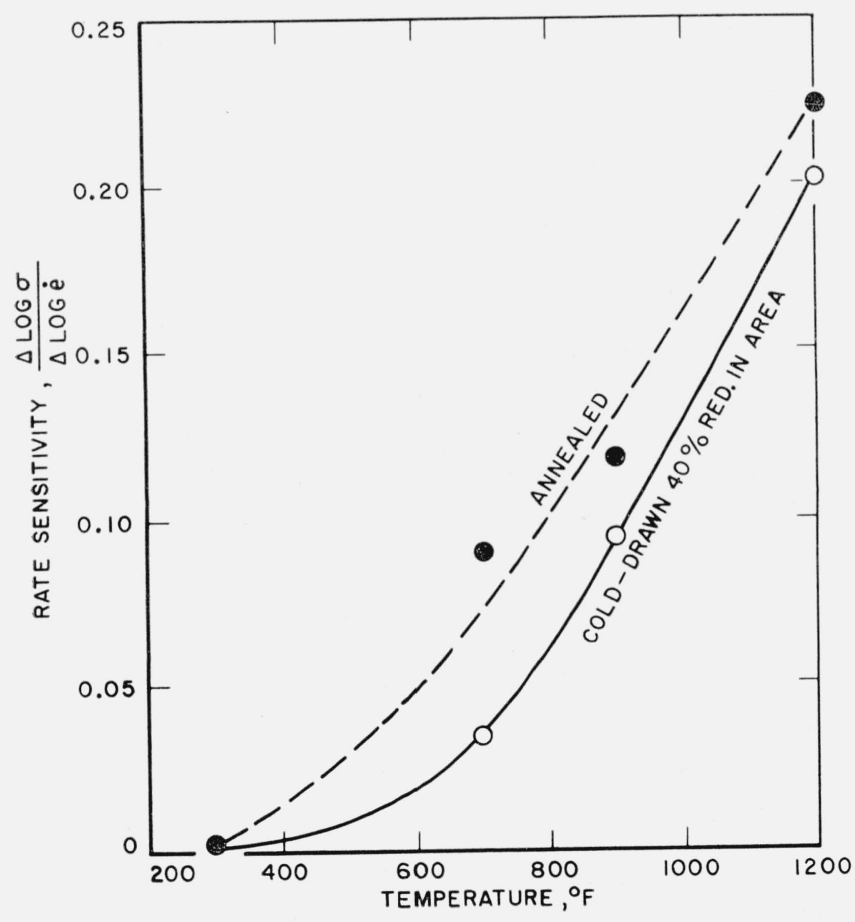

Figure 6. Relation of temperature to the rate sensitivity of annealed and cold-drawn nickel.

\subsection{Effect of Stress, Temperature and Creep Rate on Fracture Time}

The relation between stress and fracture time for the cold-drawn nickel is shown in figure 8 . The breaks in the curves, such as those occurring for specimens tested at $900^{\circ}$ and $1,200^{\circ} \mathrm{F}$, are generally interpreted as an indication of an abrupt change in the mode of fracture. Transcrystalline fractures

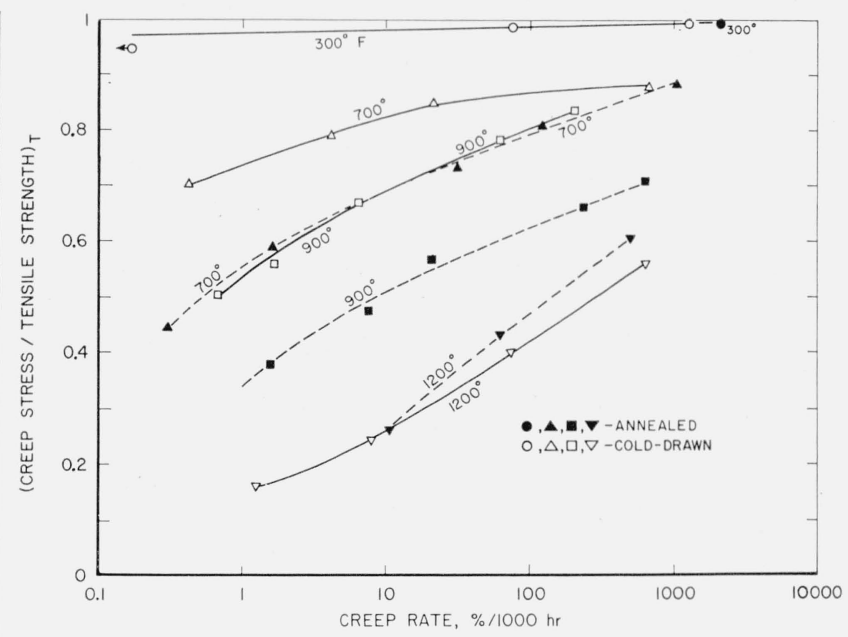

FiguRE 5. Relation of creep stress-tensile strength ratio (at temperature $\mathrm{T}$ ) to the average second-stage creep rate of annealed and cold-drawn nickel.

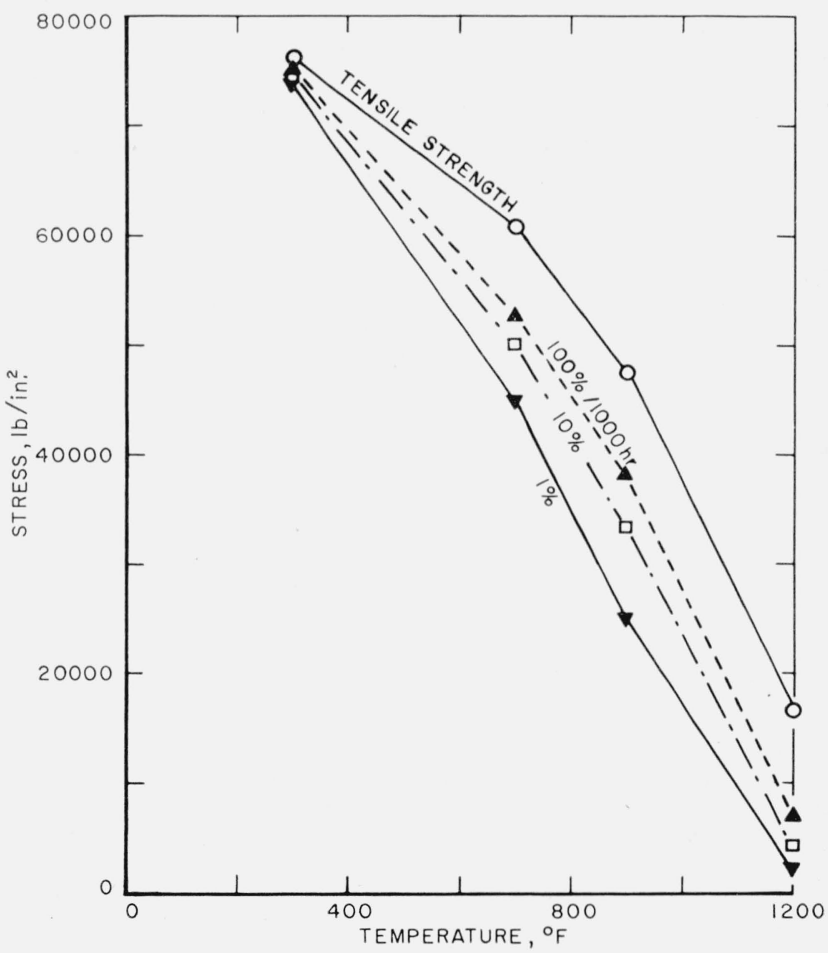

FIGURE 7. Variation of stress with temperature required to produce second-stage creep rates in the cold-drawn nickel.

The effect of temperature on the tensile strength is also shown.

were associated with the relatively short fracture times and intercrystalline fractures with longer fracture times.

Monkman and Grant [16] have proposed that the relation between "rupture life" and "minimum creep rate" could be expressed by an equation of the form:

$$
\log t_{\tau}+m \log \dot{e}=K_{1}
$$




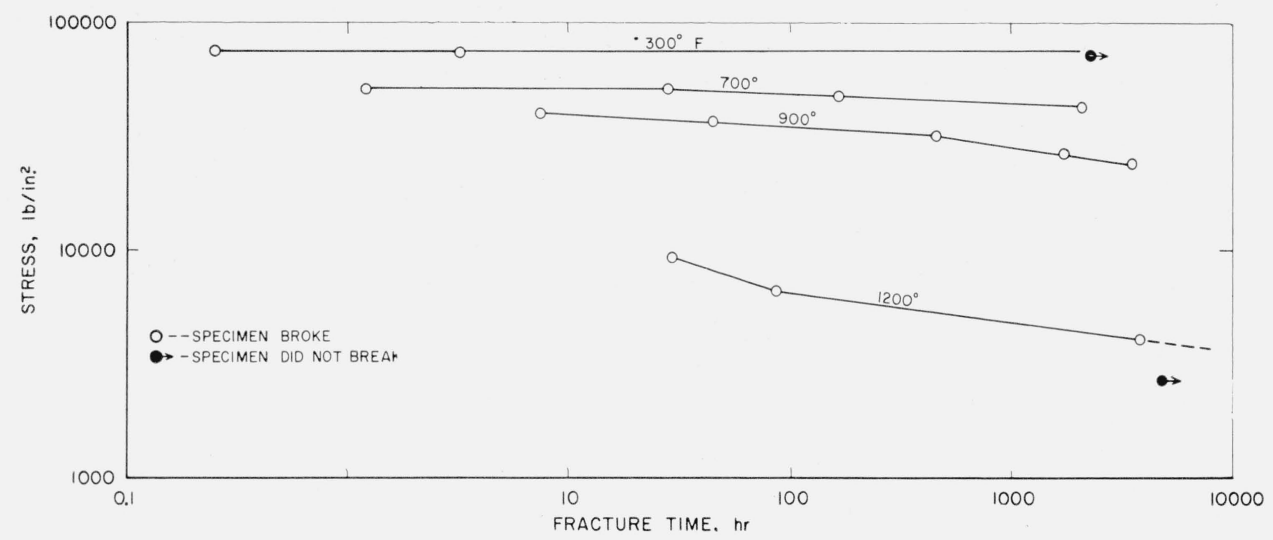

Figure 8. Relation of stress to fracture time for the cold-drawn nickel.

where $t_{r}=$ rupture life (fracture time), $\dot{e}=$ minimum creep rate (creep rate, second stage), and $m$ and $K_{1}=$ constants.

Within experimental error the equation was conidered to be independent of testing temperature, stress, chemical composition, hardness or structure; however, the ductility (elongation or reduction of area values) at fracture appeared to affect this relationship.

The effect of temperature on the relation between log fracture time and log second-stage creep rate for both the annealed and the cold-drawn nickel is shown in figure 9. With the exception of the data for the specimens tested at $1,200^{\circ} \mathrm{F}$ and one specimen tested at $900^{\circ} \mathrm{F}$ at a fast creep rate, the slopes of the linear portion of these curves appear to be independent of temperature and of cold-drawing. The curvature of the curves for the cold drawn and the annealed specimens tested at $1,200^{\circ} \mathrm{F}$ are similar in shape and give evidence of the effect of simultaneous creep and recrystallization on this relationship. Due to its greater ductility, the curves for the annealed nickel are above those of the cold-drawn nickel.

Numbers of parameters have been proposed to describe the relation of stress to temperature and either fracture time or creep rate. Two of the first of these were proposed by Larson and Miller [17] and are of the form:

$$
\left(T_{R}\right)(a+\log t)=f(\sigma),
$$

or

where

$$
\left(T_{R}\right)(a-\log r)=f_{1}(\sigma) .
$$

$f(\sigma)$ and $f_{1}(\sigma)$ are functions of the stress, $T_{R}$ is absolute temperature in degrees Rankine, $a$ is a constant $(20)$,

$t$ is rupture time (fracture time) in hours, and $r$ is creep rate in percent per hour.

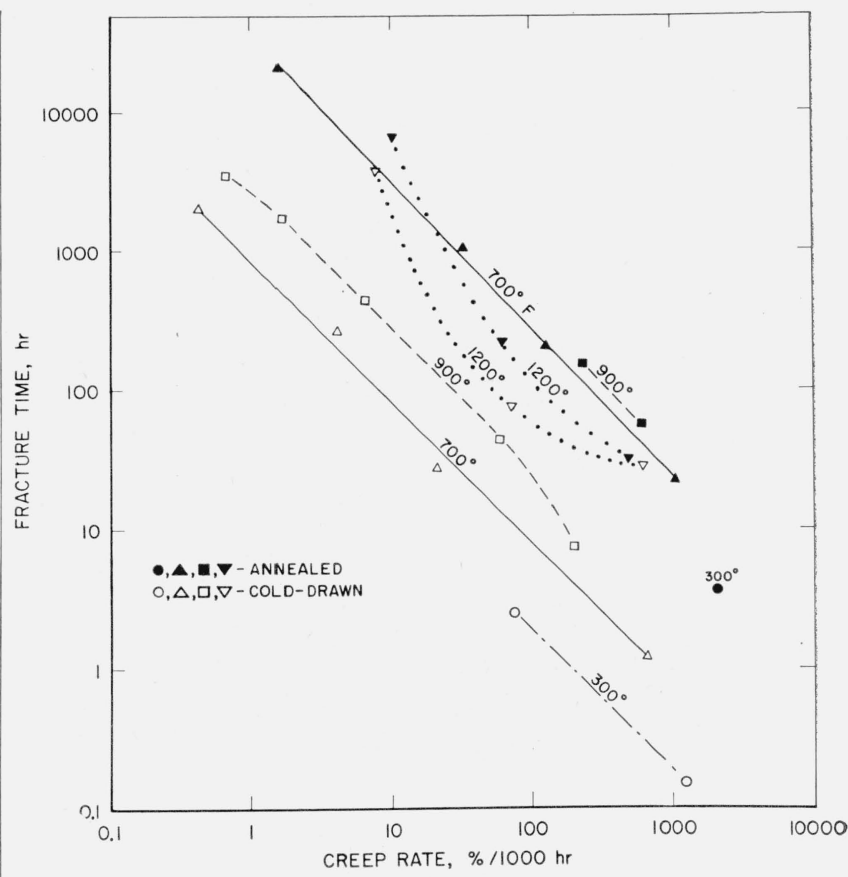

FIGURE 9. Relation of fracture time to the average second-stage creep rate of cinnealed [5] and cold-drawn nickel.

Although the validity of the proposed parameters has been questioned, it appears that this is a useful means of cataloging engineering data and for interpolation. However, usage in extrapolation over wide ranges of stresses and temperatures may involve large errors.

The effects of cold-drawing on these stress-parameter relations are shown in figure 10 . The curves for the cold-drawn nickel are above those of the annealed nickel at the low temperatures (low parameter values). However, an approximate coincidence of the two curves is observed for specimens tested at $1,200^{\circ} \mathrm{F}$. This occurred for values of $35 \times 10^{3}$ or greater for the parameter involving fracture time (fig. 10.A) and $27 \times 10^{3}$ for the parameter involving creep rate (fig. 10B). 


\subsection{Effect of Temperature and Creep Rate on Ductility and Fracturing Characteristics}

The relation between second-stage creep rate and elongation and reduction of area values of annealed and cold-drawn specimens of the nickel tested to fracture at $700^{\circ}, 900^{\circ}$, and $1,200^{\circ} \mathrm{F}$ is shown in figure 11. Insufficient data were available to evaluate this relation at $300^{\circ} \mathrm{F}$. Cold-drawing reduced the elongation markedly and the reduction of area slightly at $700^{\circ}$ and $900^{\circ} \mathrm{F}$, whereas at $1,200^{\circ} \mathrm{F}$ no consistent relation was observed. Moreover, the elongation and reduction of area values appear, with few exceptions, to be less dependent on the creep rate than on the temperature.

The relation between true stress and true strain at fracture for cold-drawn specimens tested at different temperatures is shown in figure 12 . These values were calculated on the basis of the minimum diameter of the specimens at room temperature and after fracture. Although some scatter is apparent, the general trend, with one major exception, is for the true strain at constant temperature to increase only slightly with an increase in true stress. However, at a constant stress, increase in strain with temperature is apparent. These results are in agreement with those found previously for the annealed nickel [5].

Some of the processes occurring during the third stage of creep preceding fracture of the initiallyannealed nickel were previously discussed [8]. It was also pointed out that the necking characteristics and hardness of the specimens were influenced by the test temperature, creep rate, and rate of loading. The effects of temperature and creep rate in the second stage on the specimen contours and on the room-temperature post-test hardness values for some of the cold-drawn nickel specimens are shown in figure 13. Specimens 8, 10, and 16 exhibited the greatest tendency toward the formation of an acute neck whereas the least tendency toward this phenomenon was shown by specimen 6 (fig. 13A). The former specimens were tested at $700^{\circ}$ or $900^{\circ} \mathrm{F}$, whereas the latter specimen was fractured at $1,200^{\circ} \mathrm{F}$ with a slow creep rate. It may also be observed that the tendency toward localized
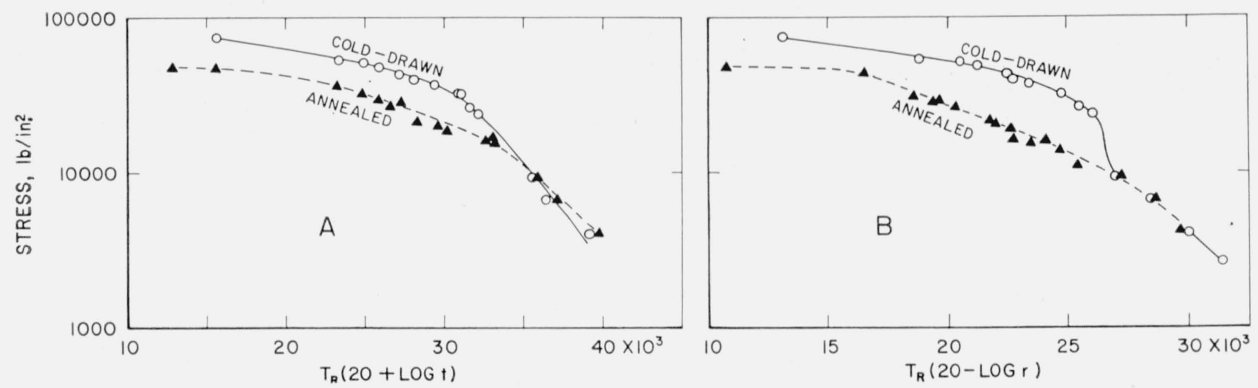

Figure 10. Relation of creep stress to fracture-time or creep-rate parameters for the annealed [5] and cold-drawn nickel.

$t=$ fracture time $(\mathrm{hr}), T_{R}=$ temperature $\left({ }^{\circ} R\right)$, and $r=$ second-stage creep rate $(\% / \mathrm{hr})$
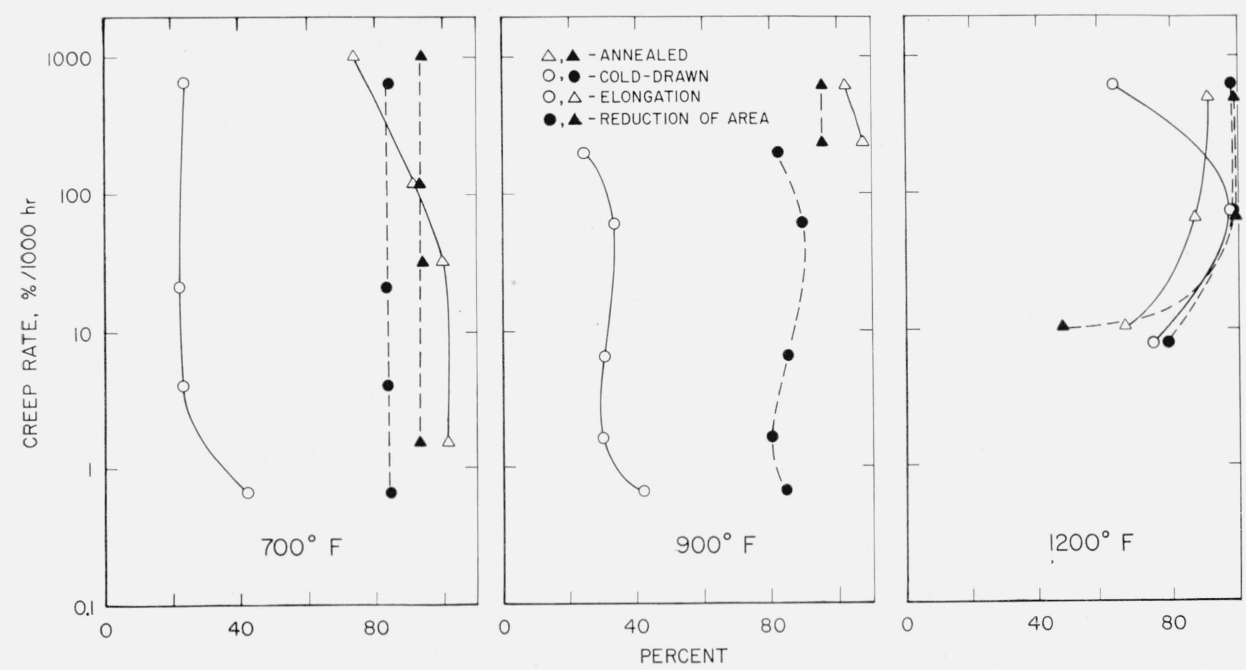

Figure 11. Relations of second-stage creep rate and elongation and reduction of area for the annealed [5] and cold-drawn nickel. 


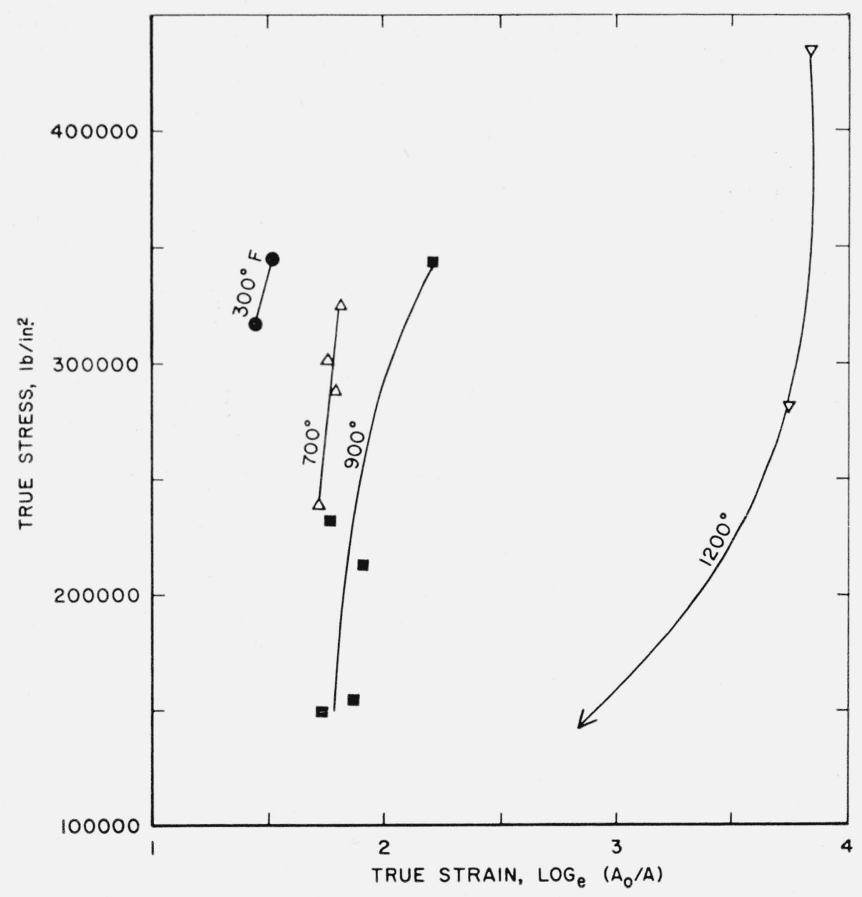

Figure 12. Relation of true stress to true strain of the colddrawn nickel.
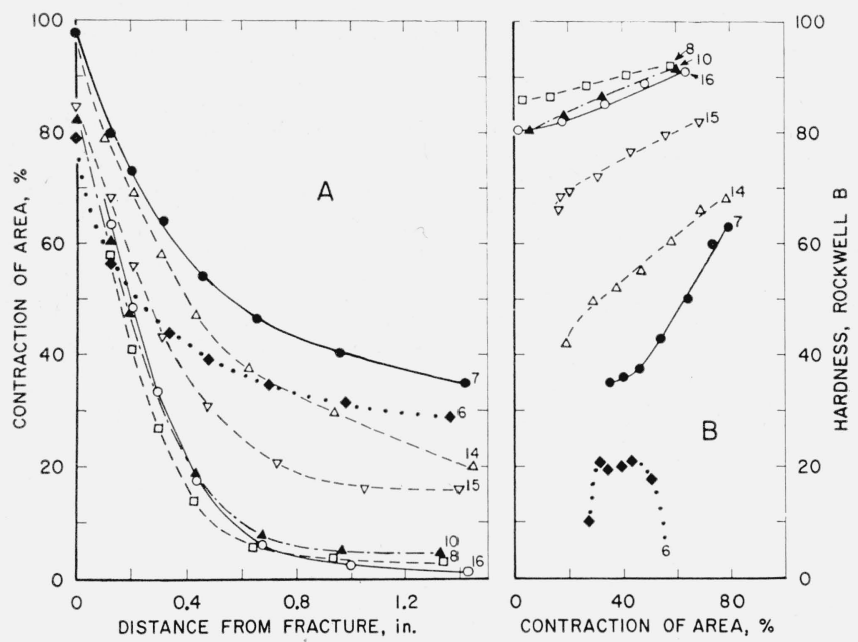

Figure 13. Contour and hardness distribution of fractured specimens of cold-drawn nickel.

\begin{tabular}{|c|c|c|}
\hline $\begin{array}{l}\text { Specimen } \\
\text { number }\end{array}$ & $\begin{array}{c}\text { Temper- } \\
\text { ature }\end{array}$ & $\begin{array}{l}\text { Creep rate } \\
\text { second stage }\end{array}$ \\
\hline 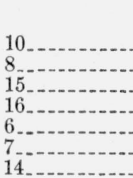 & $\begin{array}{r}{ }^{\circ} F \\
700 \\
700 \\
900 \\
900 \\
1,200 \\
1,200 \\
1,200\end{array}$ & $\begin{array}{c}\% / 1,090 h r \\
0.42 \\
670 . \\
0.67 \\
200 . \\
7.9 \\
72.6 \\
632 .\end{array}$ \\
\hline
\end{tabular}

necking decreased with increase in temperature or with decrease in creep rate (at constant temperature). The influence of creep rate on necking characteristics of the specimens is less pronounced at the low test temperature.

All the specimens, except number 6, exhibited a tendency toward an increase in hardness with increase in contraction of area values (fig. 13B). As will be shown later, specimen 6 also showed a marked tendency toward recrystallization and grain growth accompanying deformation. Furthermore, for any constant value of contraction of area, the hardness decreased with increase in test temperature and with decrease in creep rate. The difference in hardness values of the specimens tested at the lower temperatures was less than the corresponding differences at the higher temperatures.

\subsection{Effect of Creep Conditions on Structures}

Limited surface cracking and extensive elongation of the grains in the direction of straining were evident for all the cold-drawn specimens tested at $300^{\circ}, 700^{\circ}$, or $900^{\circ} \mathrm{F}$. This was also observed for the annealed nickel [5]. High ductility accompanied by extensive surface cracking was observed for the colddrawn specimens tested to fracture at $1,200^{\circ} \mathrm{F}$, as shown in figure 14 . The extent of the cracking decreased as the creep rate was increased. The structure near the axis adjacent to the fracture of these three specimens is shown in figure 15. Extensive grain elongation is evident in the specimen tested at the fastest rate (fig. 15A) whereas small equiaxed recrystallized grains were predominant in the specimen tested at a slower rate (fig. 15B). Complete recrystallization, accompanied by grain growth and intercrystalline cracking, is evident in the specimen tested to fracture at a much slower rate (fig. $15 \mathrm{C}$ ).

These three specimens were selected for a detailed metallographic examination. In addition, another creep specimen tested into the third stage of creep at $1,200^{\circ} \mathrm{F}$ for $4,853 \mathrm{hr}$ without complete fracture (table 1) was examined. Several other unstressed specimens were annealed at different temperatures to ascertain the influence of temperature only on the structures.

By varying the etchants and the etching or photographic techniques, several characteristic features of the nickel were observed. These features and the etching procedures were as follows:

(1) Grain size and intercrystalline cracks were revealed by moderately-deep etching (about $1 \mathrm{~min}$ ) in six parts concentrated nitric acid and four parts glacial acetic acid.

(2) Etch pits and subgrain boundaries were revealed by deep etching for about $6 \mathrm{~min}$ in the above solution.

(3) "Etch figures" of tertiary and quaternary symmetry were revealed by etching first in the above solution for $3 \mathrm{~min}$; second, in a solution of six parts concentrated nitric acid and four parts amyl acetate for $2 \mathrm{~min}$; and third, in a solution of five parts con- 

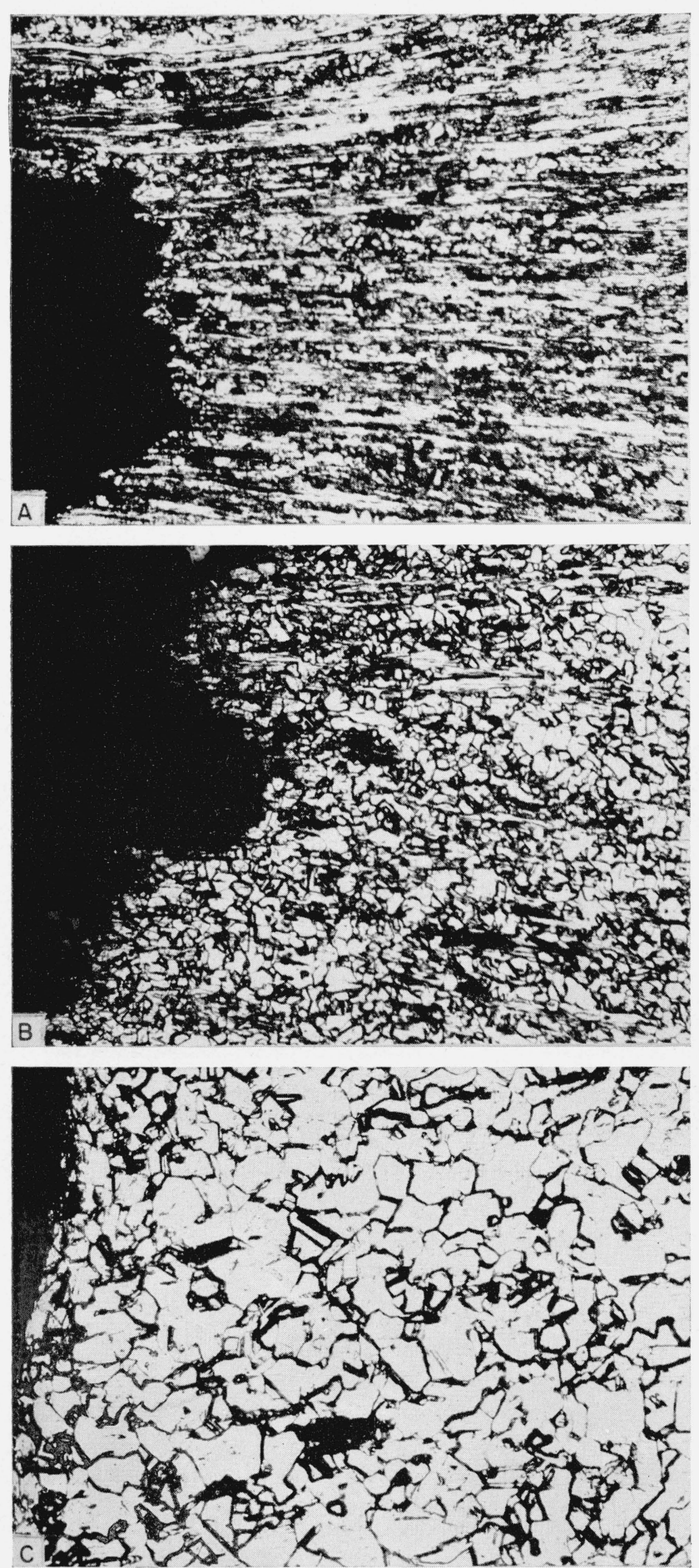

FIGURE 15. Structure of the cold-drawn nickel after fracturing in creep at $1,200^{\circ} \mathrm{F}$.

Longitudinal sections at fracture surface near axis; etched in 6 parts of $\mathrm{HNO}_{3}$ conc.) and 4 parts of glacial acetic acid. $(\times 100)$

\begin{tabular}{|c|c|c|c|}
\hline & Creep rate & $\begin{array}{l}\text { Elonga- } \\
\text { tion in } \\
2 \text { in. }\end{array}$ & $\begin{array}{l}\text { Reduc- } \\
\text { tion of } \\
\text { area }\end{array}$ \\
\hline & $\begin{array}{c}\% / 1,000 \mathrm{hr} \\
632\end{array}$ & $\begin{array}{l}\% \\
62.5\end{array}$ & ${ }^{\%} 97.8$ \\
\hline & $\begin{array}{r}72.6 \\
7.9\end{array}$ & $\begin{array}{l}97.3 \\
74.5\end{array}$ & $\begin{array}{l}97.6 \\
78.8\end{array}$ \\
\hline
\end{tabular}

temperatures for one hour, polished and etched. Microstructures of these specimens are shown in figure $17 \mathrm{~A}, \mathrm{~B}$ and $\mathrm{C}$. An etch figure produced on the surface of a single crystal of nickel ${ }^{3}$ is shown, for comparison, in figure $17 \mathrm{D}$. The size of the largest etch figures increased with increase in annealing temperature or grain size and decreased with increasing hardness.

It was observed in high-purity copper [1] that, at low stresses or high temperatures, cracking was often initiated at the surface and progressed toward the axis during the third stage of creep. Intercrystalline cracking near the surface of two specimens of highpurity nickel, tested at $1,200^{\circ} \mathrm{F}$, is shown in figure 18. One of the specimens (fig. 18A) was tested in creep into the third stage; the other specimen (fig. 18B) was tested to complete fracture. Although the time at temperature for the former specimen was longer $(4,853 \mathrm{hr})$ than the latter $(3,825 \mathrm{hr})$, the cracking in the latter specimen had progressed much farther into the interior of the specimen. This observation indicates that the extent of intercrystalline cracking is a function of the total strain as well as of the strain rate.

One consequence of high-temperature creep appears to be that high-angle (high-energy) grain boundaries are less evident at the high temperature as shown for some of the adjacent grains with the triangular etch figures in figure 19. Boundaries of this type are considered to be less effective barriers to the motion of dislocations, and thus contribute more to the weakness of the metal, than the highangle boundaries observed after creep at the lower temperatures. The neighboring grains, separated by low-angle grain boundaries, are less susceptible to intercrystalline cracking (fig. $20 \mathrm{~A}$ and $\mathrm{B}$ ) than those separated by the high-angle grain boundaries (fig. $20 \mathrm{C}$ and $\mathrm{D}$ ). The grain boundary (fig. 20D) may have acted as a barrier to the continued motion of the dislocations, or the crack may have acted as a source for the concentration of etch figures near the intercrystalline crack. This phenomenon is practically nonexistent in the structures shown in figures 19 and $20 \mathrm{~A}$ and $\mathrm{B}$.

Subgrains within the parent grains of high-purity nickel have been observed for a number of years $[20,21]$. The nature and the distribution of etch pits within the subgrains and at the subgrain boundaries, as a consequence of high temperature annealing, was recently discussed by Feltham [22]. Parker and Hazlett [23] suggested that the dislocation types of substructure boundaries sometimes have a more marked effect on strengthening than does solution-hardening. The distribution of subgrains and etch pits in a specimen of cold-drawn nickel, tested into the third stage of creep $(4,853 \mathrm{hr})$ at $1,200^{\circ} \mathrm{F}$, is shown in figure 21. A general estimation of etch pit density was impossible as the number appeared to very from grain to grain and even within different areas of the same grain. Part of a grain that is densely populated with etch pits and contains small subgrains having dislocation boundaries

3 The crystal was produced for another project in this laboratory and possessed approximately the same composition as the material used in this investigation 

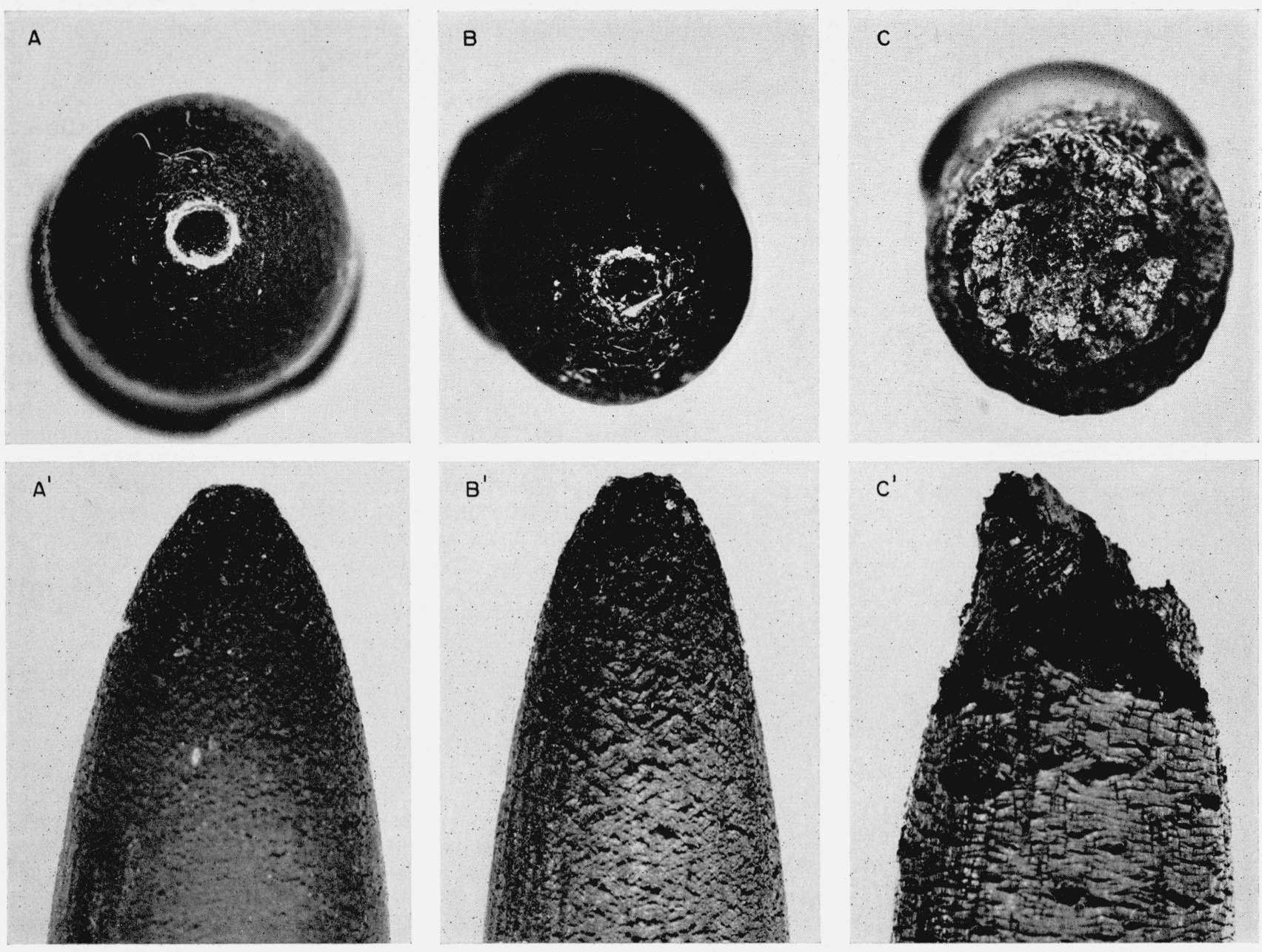

FIGURE 14. Appearance of specimens of cold-drawn nickel fractured at $1,200^{\circ} \mathrm{F}$ at different rates. (X 5)

\begin{tabular}{|c|c|c|c|}
\hline & $\begin{array}{l}\text { Creep } \\
\text { rate, } \\
\text { second } \\
\text { stage }\end{array}$ & $\begin{array}{l}\text { Elonga- } \\
\text { tion in } \\
2 \text { in. }\end{array}$ & $\begin{array}{l}\text { Reduc- } \\
\text { tion of } \\
\text { area }\end{array}$ \\
\hline $\begin{array}{l}\mathrm{A}, \mathrm{A}^{\prime} \\
\mathrm{B}, \mathrm{B}^{\prime} \\
\mathrm{C}, \mathrm{C}^{\prime}\end{array}$ & $\begin{array}{r}\% / 1,000 \mathrm{hr} \\
632 . \\
72.6 \\
7.9\end{array}$ & $\begin{array}{l}\% \\
62.5 \\
97.3 \\
74.5\end{array}$ & $\begin{array}{l}\% \\
97.8 \\
97.6 \\
78.8\end{array}$ \\
\hline
\end{tabular}

centrated nitric acid and five parts glacial acetic acid for $5 \mathrm{~min}$. This procedure is hereafter termed "triple etch."

Triangular and square etch figures, produced by etching the nickel after testing in creep at $1,200^{\circ} \mathrm{F}$ under different stresses, are shown in figure 16 . Lacombe and Beaujard [18] have shown that the equilateral triangular figures in aluminum were associated with the surface parallel to the (111) plane and the square figures were associated with the surface parallel to the (100) plane. More recently Wernick et al. [19] indicated that triangular etch pits could be produced and randomly dispersed on the (111) plane and that the pits were formed at dislocation sites. There was a predominance of triangular etch figures produced in the specimens examined in the present investigation. The largest size of the triangular figures (etching times and procedures constant) increased with increase in test time or decrease in creep rate. This is in accordance with known relations between slip-band spacing and creep rate and is probably associated with the ability of the atmospheres to move with the dislocations.

In order to ascertain the effect of temperature, in the absence of an applied stress, on the size of the etch figures, specimens were annealed at several 


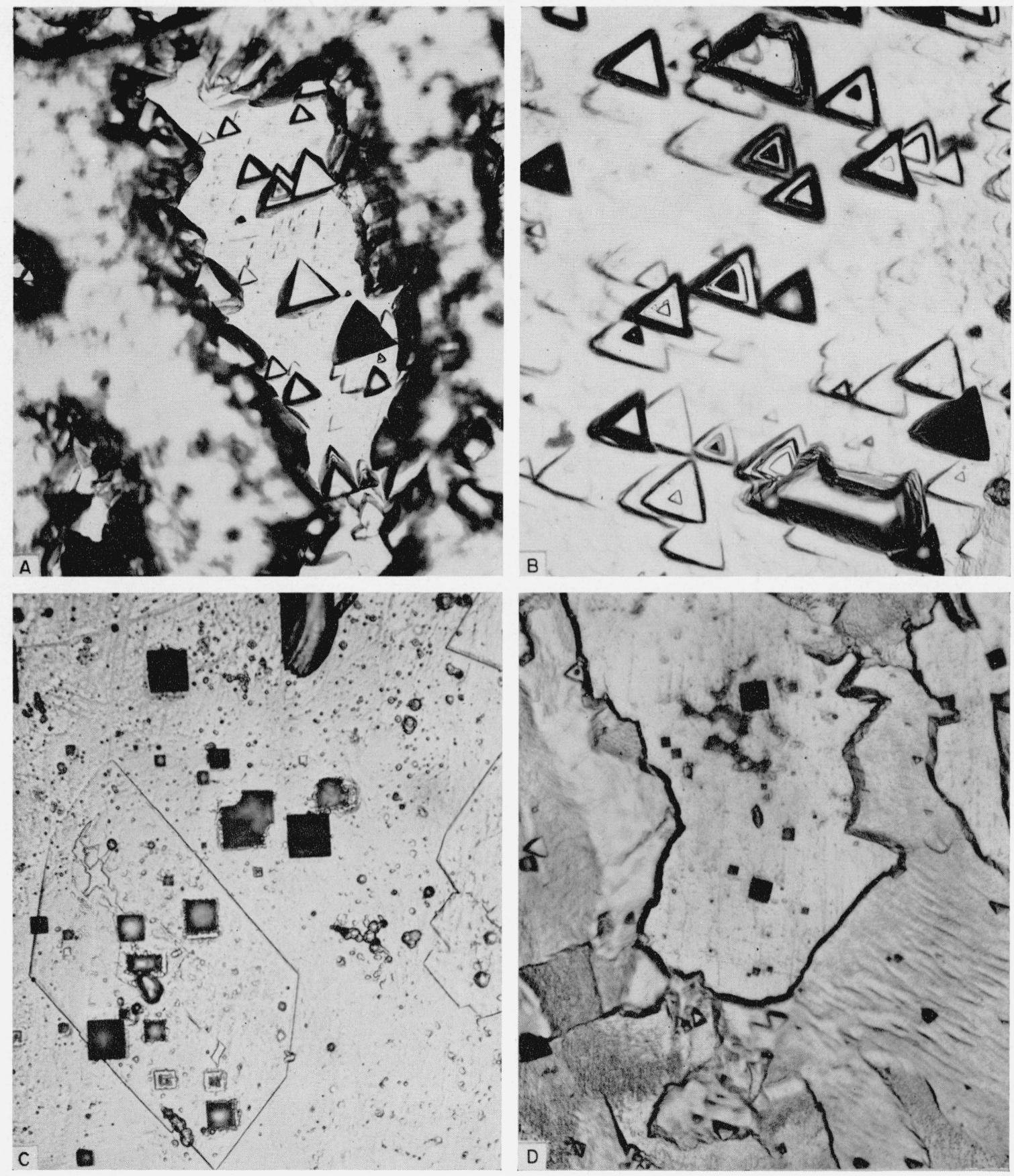

FIGURE 16. Etch figures in the cold-drawn nickel after creep-testing in tension at $1,200^{\circ} \mathrm{F}$ for various times at Cross section, "triple etch". $(\times 500)$. different stresses.

\begin{tabular}{|c|c|c|c|}
\hline & Stress & $\begin{array}{l}\text { Creep rate, } \\
\text { second stage }\end{array}$ & Time \\
\hline $\begin{array}{l}\mathrm{A} \\
\mathrm{B} \\
\mathrm{C} \\
\mathrm{D} \\
\mathrm{D}\end{array}$ & $\begin{array}{c}l b / \text { in }_{2} .^{2} \\
9,330 \\
2,665 \\
2,665 \\
6,670\end{array}$ & $\begin{array}{r}\% / 1,000 h r \\
632 \\
1.24 \\
1.24 \\
72.6\end{array}$ & $\begin{array}{c}h r \\
28 . \\
4,853 \\
4,853 \\
86\end{array}$ \\
\hline
\end{tabular}




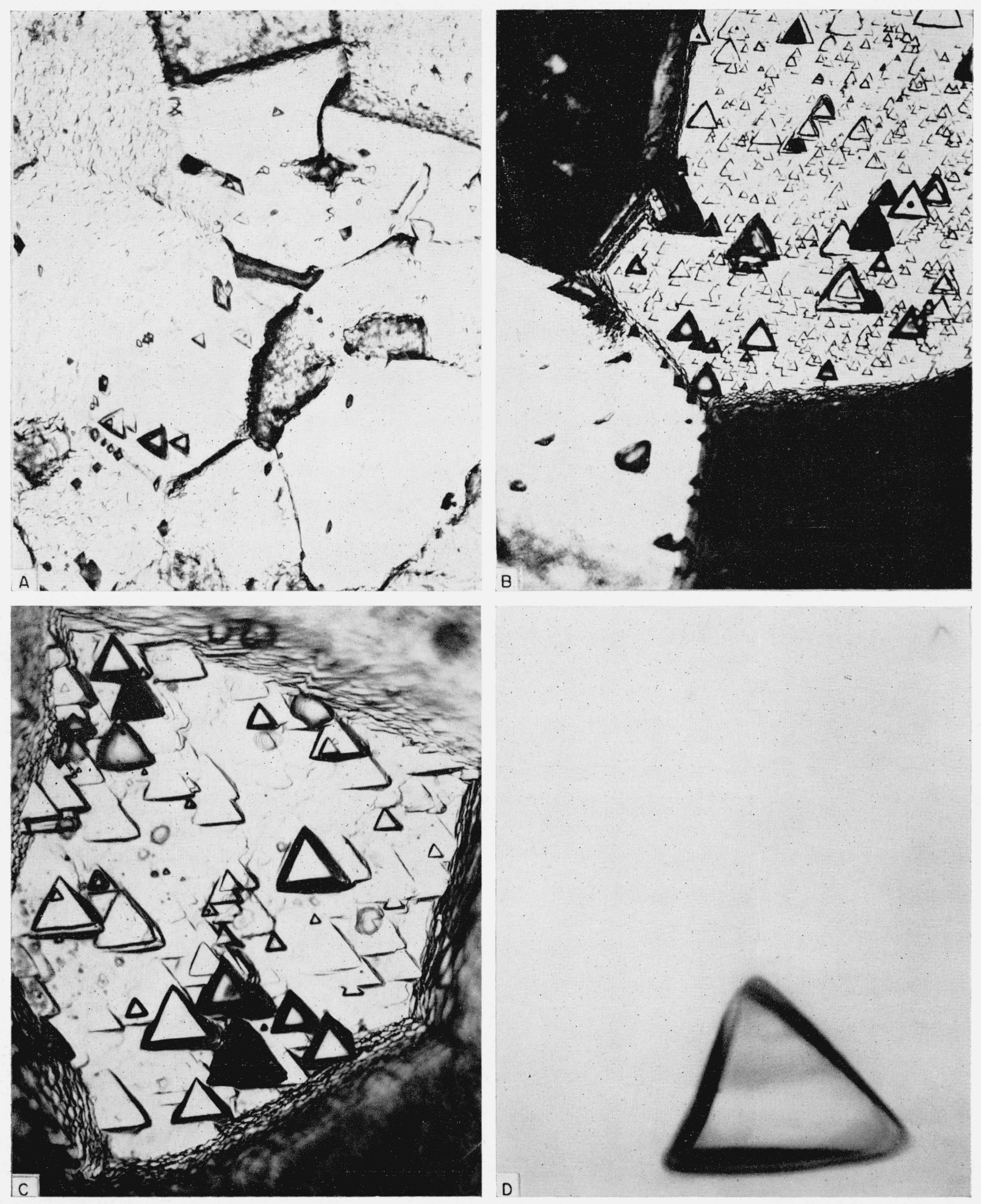

FIGURE 17. Effect of annealing temperature or grain size on the size of etch figures in nickel. Longitudinal sections, “triple etch"” $(\times 500)$.
A, $1,100^{\circ} \mathrm{F} ; \mathrm{B}, 1,500^{\circ} \mathrm{F} ; \mathrm{C}, 1,800^{\circ} \mathrm{F} ; \mathrm{D}$, single crystal, produced from a different lot of high-purity nickel. 


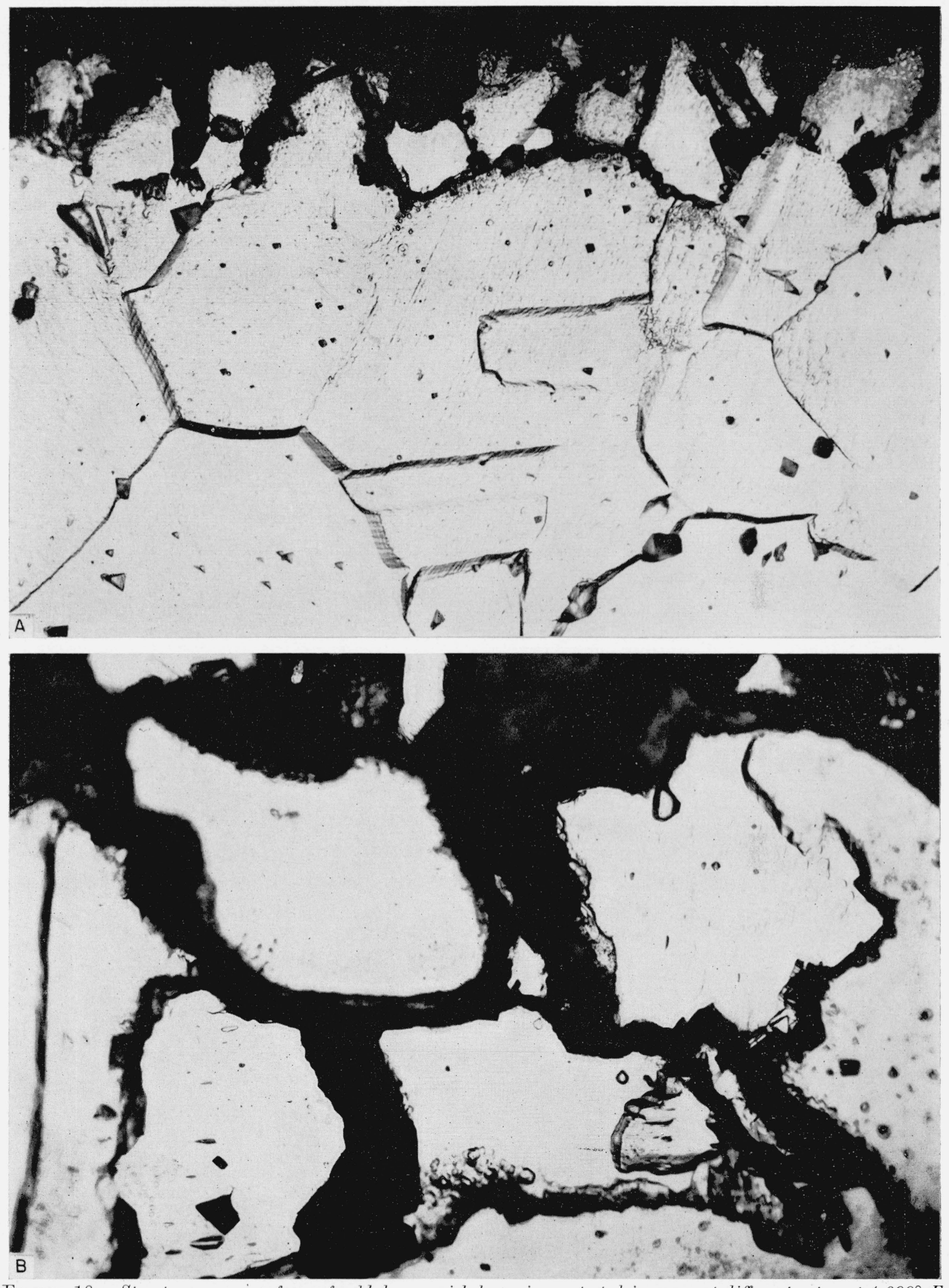

FIGURE 18. Structure, near surface, of cold-drawn nickel specimens tested in creep at different rates at $1,200^{\circ} F$. Longitudinal sections, etched in 6 parts $\mathrm{HNO}_{3}$ (conc.) and 4 parts glacial acetic acid. ( $\left.\times 500\right)$.

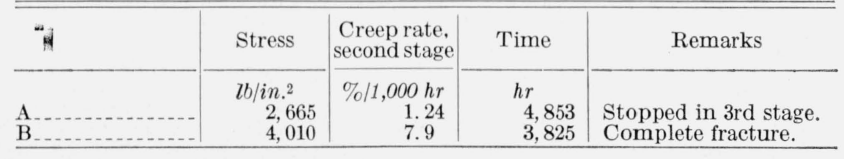




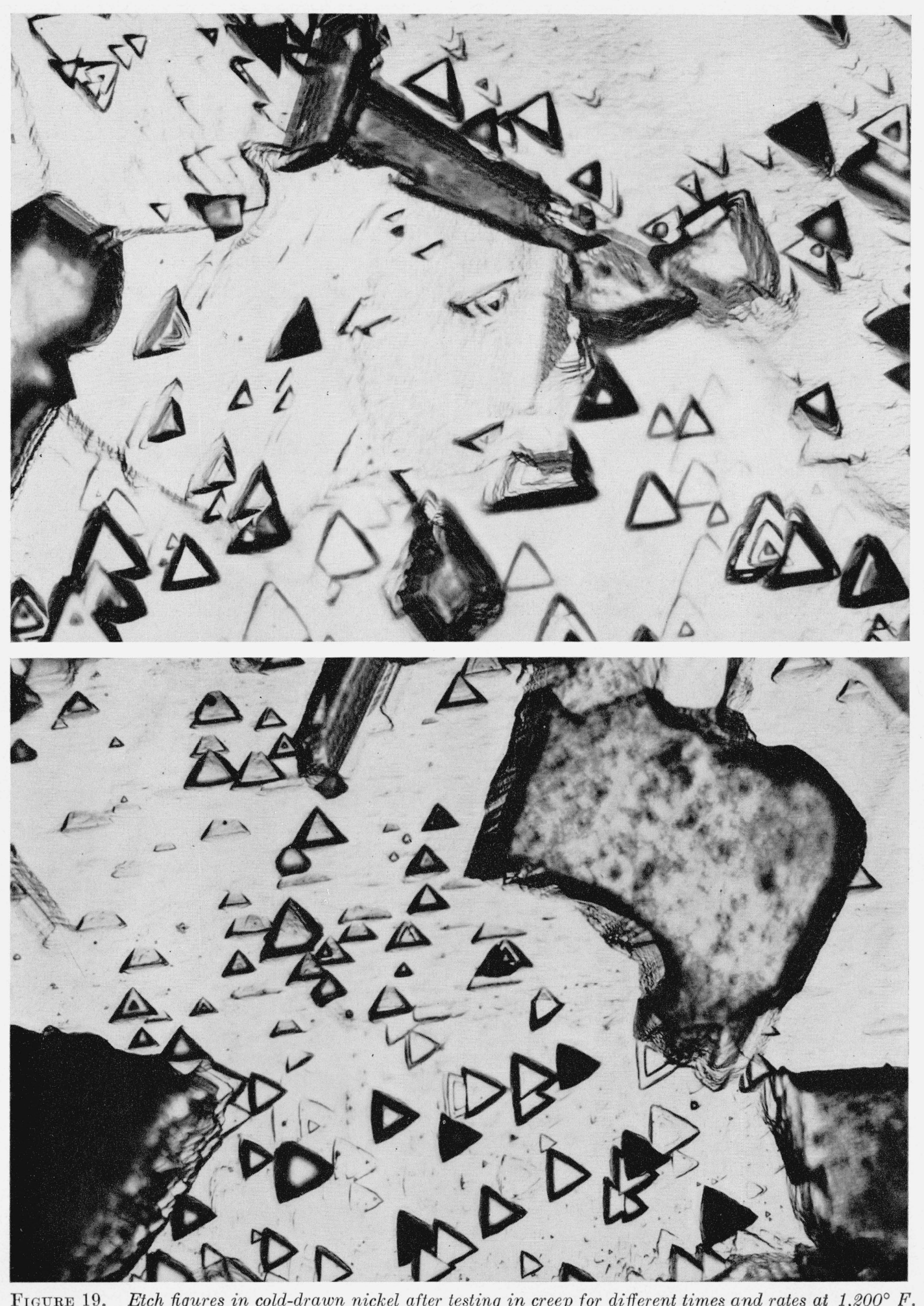

Longitudinal sections of the same specimen shown in figure 18, "triple etch". (X 500).

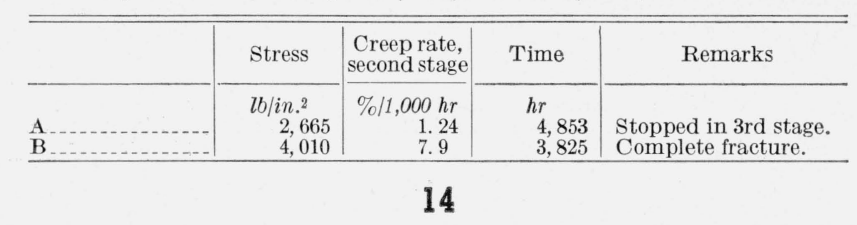



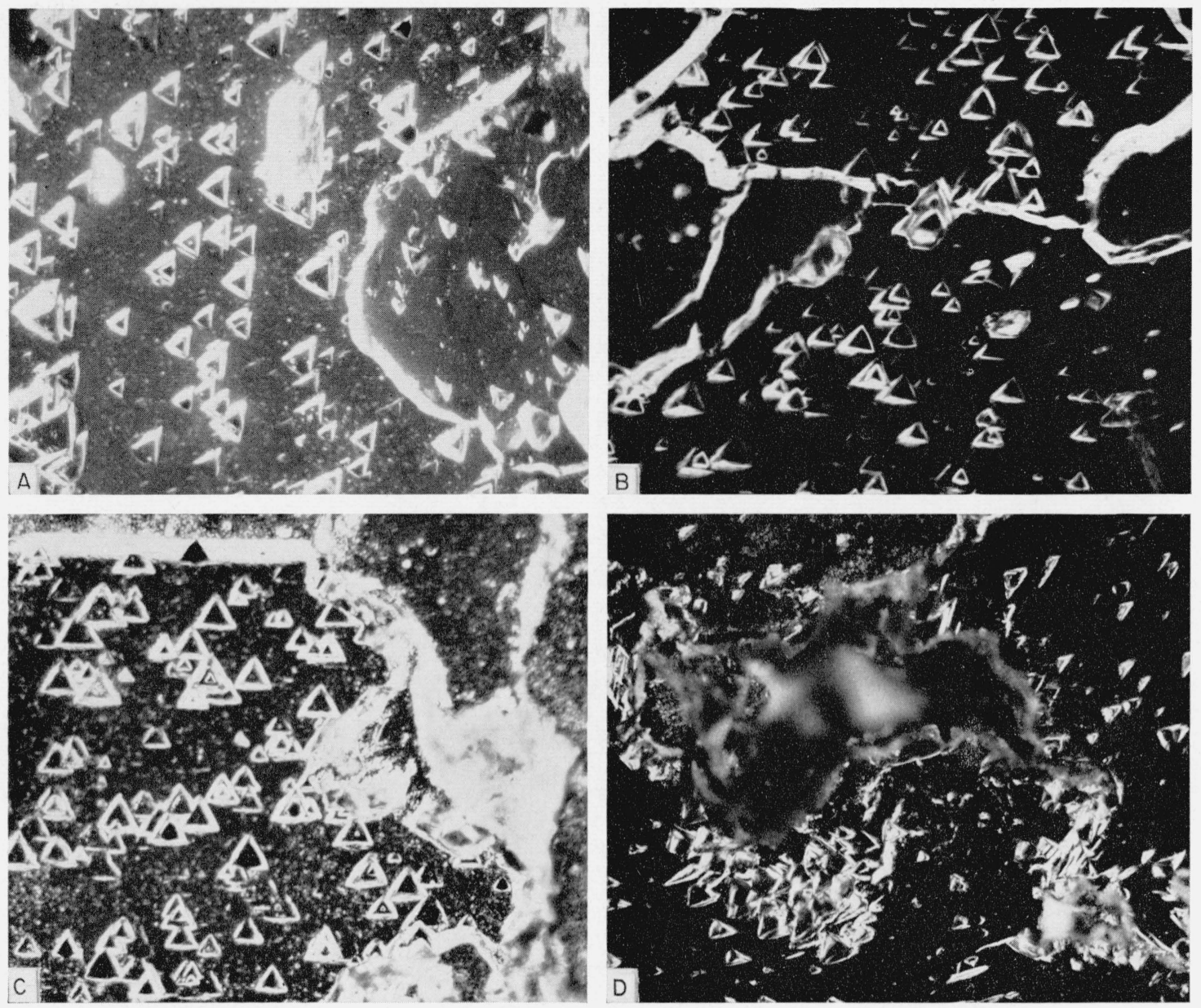

FIGURE 20. Etch figures in a cold-drawn nickel specimen tested to complete fracture in creep in 3,825 hr at $1,200^{\circ} \mathrm{F}$ under stress of $4010 \mathrm{lb} / \mathrm{in} .^{2}$.

Cross section of same specimen as B in figures 18 and 19. $0.25 \mathrm{in}$. from fracture. A and B illustrate low-angle boundaries; C and D illustrate bigh-angle boundaries; "Triple etch", dark-field illumination. ( $\times 250)$.

is shown in figure $21 \mathrm{~A}$. Two grains separated by a relatively low-energy grain boundary are shown in figure 21B. Small subgrains are evident in each parent grain and the etch-pit density is greater near the grain boundary for the grain on the left than for the grain on the right. Larger subgrains and fewer etch pits are evident in the grain shown in figure $21 \mathrm{C}$. Portions of two grains separated by a high-energy boundary are shown in figure 21D. No subgrains were observed in one grain while the other grain appeared to be densely populated with them. The size of these subgrains appears to increase with increasing distance from the grain boundary.

Several attempts to reveal subgrains in the nickel by annealing in the absence of stress proved unsuccessful, as illustrated by the structures reproduced in figure 22. Rather, recrystallization of the cold-drawn nickel into large grains accompanied by profuse twinning occurred. Etch pits were more easily delineated at or near the grain or twin boundaries than in the interior of the grains. The density of the pits appear to be related both to the orientation of the adjacent grains and to the differences in energy along a specific boundary. Apparently, cold-drawing followed by annealing was less effective for promoting the formation of subgrains and more effective for promoting the formation of annealing twins than creep deformation of nickel at high temperatures.

\section{Summary}

Creep tests were made in tension under constant loads at temperatures of $300^{\circ}, 700^{\circ}, 900^{\circ}$, and $1,200^{\circ}$ $\mathrm{F}$ on specimens of nickel initially cold-drawn to 40 -percent reduction in area.

None of the equations proposed for defining the strain-time relationship conformed to the data for specimens tested under various conditions although conformance to the parabolic strain-time law was obtained over limited ranges of stresses and strains. This lack of conformance was attributed to the structural changes that occurred at the different temperatures and stresses. 

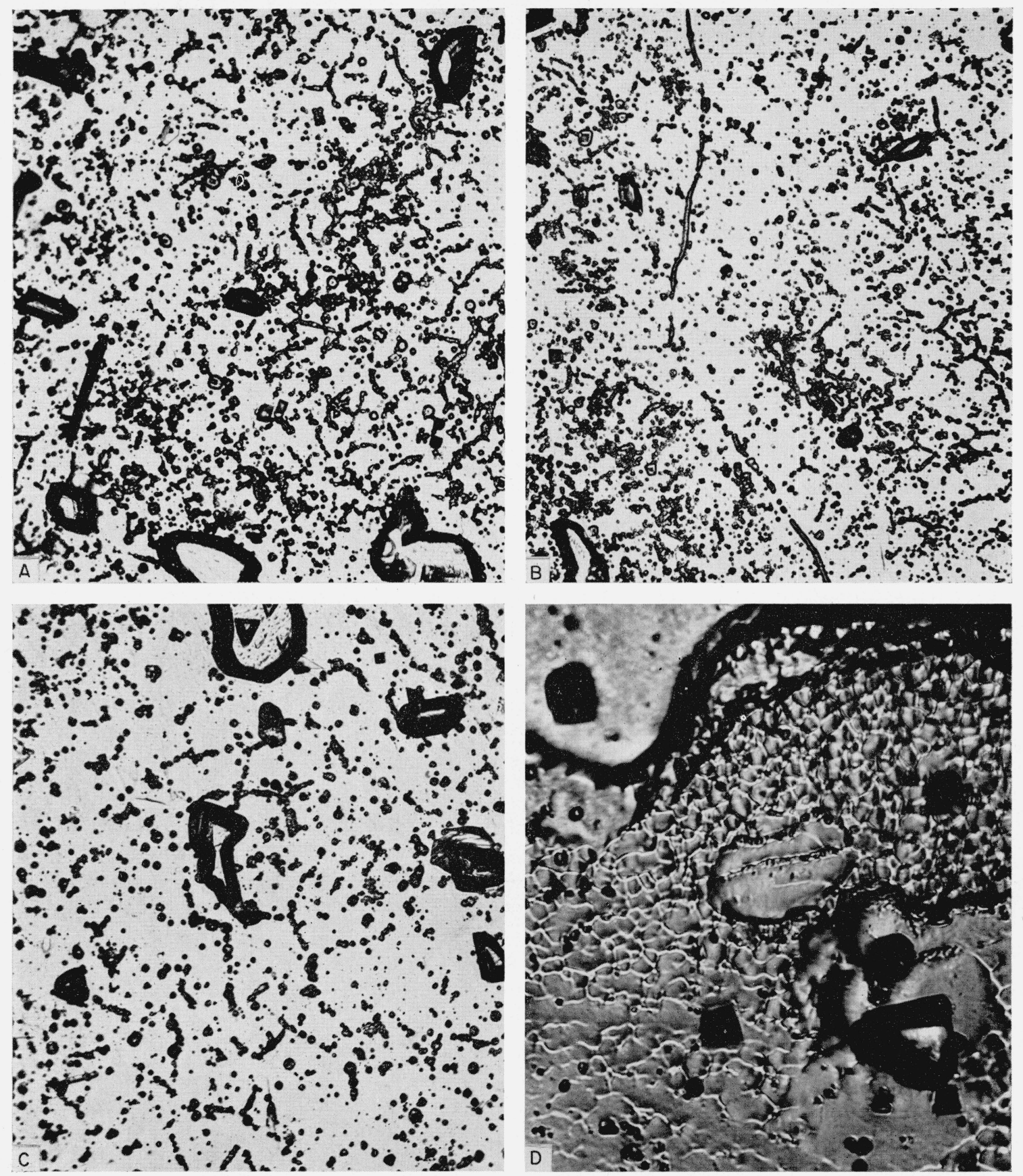

FIGURE 21. Subgrains and etch pits in a cold-drawn nickel specimen, tested in creep under a stress of 2,665 lb/in.2 at $1,200^{\circ} \mathrm{F}$ and stopped in the third stage after $4,853 \mathrm{hr}$ and 8.5 percent plastic strain.

The "rate sensitivity" of the nickel increased with increase in test temperature. At constant temperature, this value was lower for cold-drawn than for annealed nickel.

The dependence of fracture time on creep stress increased with increase in test temperature. However, in the absence of extensive recovery, the log fracture time varied linearly with log creep rate for both the annealed and the cold-drawn metal.
An evaluation of temperature-time and temperature-creep rate parameters showed that, at equal parameters, the stress values were higher for the cold-drawn than for the annealed nickel at the lower creep temperatures but the stress values coincided at $1,200^{\circ} \mathrm{F}$. Thus, the resistance of the nickel to creep at temperatures below about $900^{\circ} \mathrm{F}$ was significantly increased by cold-drawing, whereas the strengthening effect of cold drawing was eradi- 


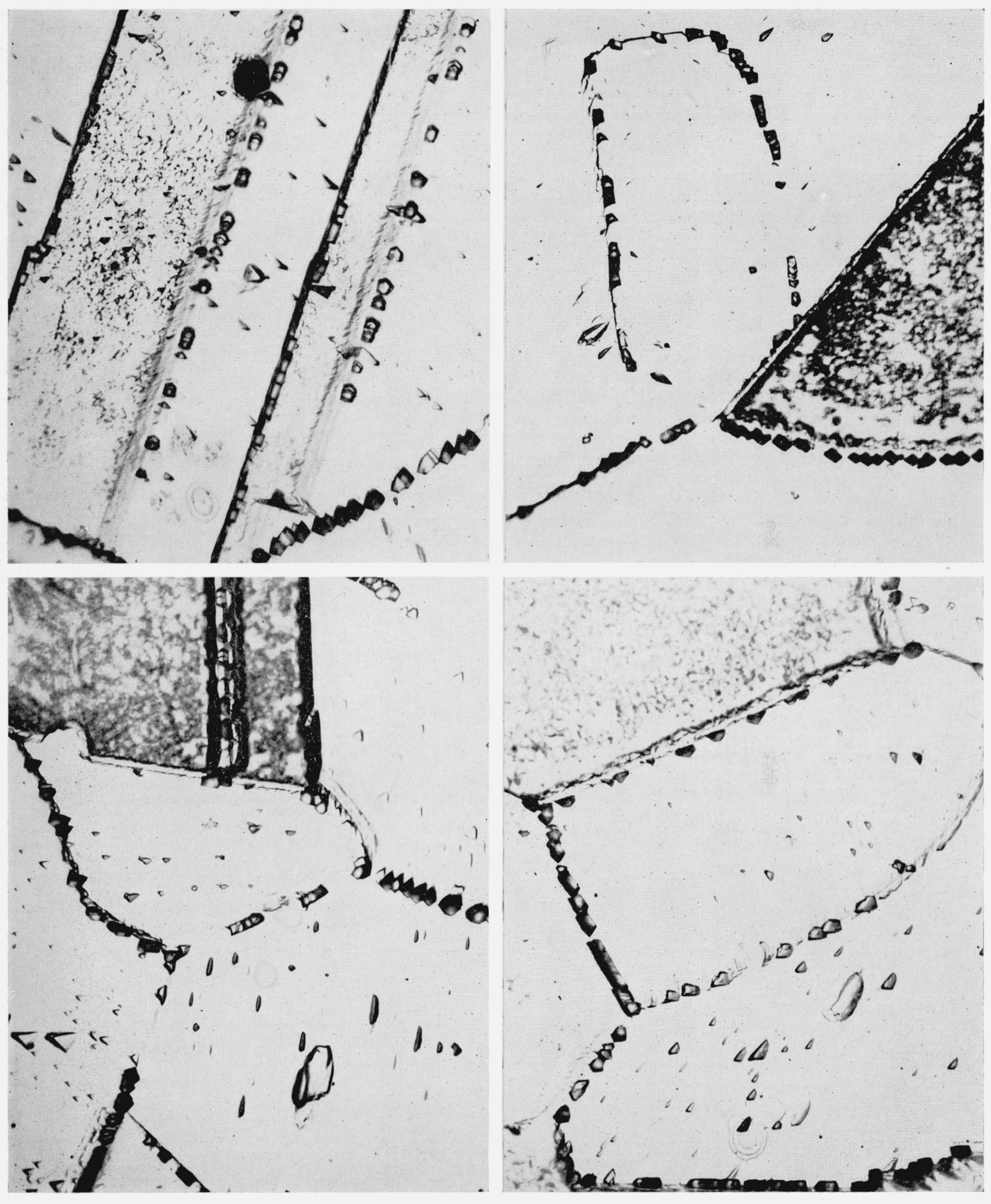

FIGURE 22. Etch-pit distribution in a nickel specimen, annealed at $1,800^{\circ} \mathrm{F}$. Longitudinal sections. Etched in 6 parts $\mathrm{HNO}_{3}$ (Conc.) and 4 parts of glacial acetic acid. $(\times 500)$. 
cated at creep temperatures above recrystallization. The increase in resistance to creep by cold-drawing was accompanied by a corresponding decrease in elongation. The reduction of area of the creep specimens was not materially changed by colddrawing. However, both the elongation and reduction of area were nearly independent of the creep rate.

True strain at fracture of the cold-drawn nickel increased with increase in temperature. The hardness of the fractured specimens decreased with increase in temperature and decrease in creep rate.

The tendency to neck decreased with increase in temperature and decrease in creep rate; moreover, the tendency to form intercrystalline cracks at the surface increased with increase in temperature and decrease in creep rate. Furthermore, the intercrystalline cracking was generally initiated at high angle boundaries. The extent of the intercrystalline cracking increased with the increase in strain.

The size of etch figures of tertiary or quaternary symmetry increased with decrease in creep rate at constant temperature or, in the absence of stress, with increase in annealing temperature.

The size and density of stress-induced subgrains appeared to be affected by the orientation of the individual grains and the relative orientations of neighboring grains.

\section{References}

[1] W. D. Jenkins and T. G. Digges, Creep of high-purity copper, J. Research NBS 45, 153 (1950) RP2121.

[2] W. D. Jenkins and T. G. Digges, Creep of annealed and cold-drawn high-purity copper, J. Research NBS 4\%, 272 (1951) RP2254.

[3] W. D. Jenkins and T. G. Digges, Effect of temperature on the tensile properties of high-purity nickel, J. Research NBS 48, 313 (1952) RP2317.

[4] W. D. Jenkins and T. G. Digges, Influence of prior strain history on the tensile properties and structures of highpurity copper, J. Research NBS 49, 167 (1952) RP2354.

[5] W. D. Jenkins, T. G. Digges, and C. R. Johnson, Creep of high-purity nickel, J. Research NBS 53, 329 (1954) RP2551.
[6] W. D. Jenkins, T. G. Digges, and C. R. Johnson, Effect of temperature on the tensile properties of a commercial and a high-purity 70-percent-nickel-30-percentcopper alloy, J. Research NBS 54, 21 (1955) RP2561.

[7] W. D. Jenkins, T. G. Digges, and C. R. Johnson, Tensile properties of copper, nickel, and 70-percent-copper30-percent-nickel and 30-percent-copper-70-percentnickel alloys at high temperatures, J. Research NBS 58, 201 (1957) RP2753.

[8] W. D. Jenkins and C. R. Johnson, Creep of annealed nickel, copper, and two nickel-copper alloys, J. Research NBS 60, 173 (1958) RP2836.

[9] Seminar on creep and recovery of metals, Trans. Am. Soc. Metals 49A (1957).

[10] T. H. Hazlett and E. R. Parker, Nature of the creep curve, Trans. AIME 19\%, 318 (1953).

[11] H. Conrad and W. D. Robertson, Creep characteristics of magnesium single crystals from $78^{\circ}$ to $364^{\circ} \mathrm{K}$, Trans. Met. Soc. AIME $\mathbf{2 1 2}, 536$ (1958).

[12] E. N. da C. Andrade, The concept of creep, Trans. Am. Soc. Metals 49A, 176 (1957).

[13] P. G. McVetty, Creep of metals at elevated temperatures. The hyperbolic-sine relation between stress and creep rate, Trans. Am. Soc. Mech. Engrs. 65, 761 (1943).

[14] S. Dushman, L. W. Dunbar, and H. Huthsteiner, Creep of metals, J. Appl. Phys. 15, 108 (1944).

[15] J. D. Lubahn, Simultaneous aging and deformation in metals, Trans. AIME 185, 702 (1949).

[16] F. C. Monkman and N. J. Grant, An empirical relationship between rupture life and minimum creep rate in creep-rupture tests, Am. Soc. Testing Materials, Proc. $\mathbf{5 6}, 593(1956)$.

[17] F. R. Larson and J. Miller, A time-temperature relationship for rupture and creep stresses, Trans. Am. Soc. Mech. Engrs. 74, 765 (1952).

[18] P. Lacombe and L. Beaujard, The application of etch figures on pure aluminum $(99.99 \%)$ to the study of some micrographic problems, J. Inst. Metals $\mathbf{7 4}, 1$ (1948).

[19] J. H. Wernick, J. N. Hobstetter, L. C. Lovell, and D. Dorsi, Dislocation etch pits in antimony, J. Appl. Phys. 29, 1013 (1958).

[20] L. Northcott, Veining or sub-boundary structures, J. Iron Steel Inst. (London) 126, 267 (1932).

[21] L. Northcott, Veining and sub-boundary structures in metals, J. Inst. Metals 59, 225 (1936).

[22] P. Feltham, Intragranular substructures in high-purity nickel, J. Inst. Metals 86, 237 (1957-58).

[23] E. R. Parker and T. H. Hazlett, Principles of solution hardening, Trans. ASM 46A, 30 (1954).

Washington, D.C.

(Paper 63C1-1) 